Rev. Elev. Méd. Vét. Pays trop., 1967, 20, 1 (27-49).

\title{
La maladie des muqueuses en Afrique centrale Observations cliniques et épizootiologiques
}

\author{
por A. PROVOST, K. BÖGEL (*), C. BORREDON el Y. MAURICE (**)
}

\begin{abstract}
RÉSUMÉ
Après avoir décrit les techniques virologiques mises en cuvre pour identifier les souches non cytopathogènes du virus de la maladie des muqueuses, les auteurs passent en revue les facteurs gouvernant l'épizootiologie de la maladie en Afrique centrale puis décrivent les particularités clinıques observées dans cette région et signalent les éléments du diagnostic. Une enquête sérologique indique que 75 p. 100 des bovins adultes possèdent des anticorps, rencontrés également chez des moutons, des antilopes et des gazelles. La répartition des anticorps par classes d'âge chez les bovins semble dénoter que la maladie des muqueuses évolue en Afrique centrale par poussées épizootiques.
\end{abstract}

Traiter de la maladie des muqueuses ne présente en 1966 rien qui soit spécialement original. Voilà vingt ans que cette virose a été individualisée en temps qu'entıté clınique aux Etats-Unis : depuis lors, on l'a signalée un peu partout dans le monde. Ubiquitaire, son importance économique varie énormément selon les régions où elle sévit, ce qui est indirectement reflété par l'importance de la littérature professionnelle la concernant. En Afrique, la moisson bibliographique est partıculıèrement maigre.

Il semble bien pourtant que les observations faites par MONTGOMERY au Kénya en 1915 se rapportent à cette maladie. Evoluant aussi bien sur des bovins immunisés contre la peste que chez d'autres réceptifs à cette dernière maladie, l'affection digestive étudiée par MONTGOMERY

(*) Détaché en 1964 du Bundesforschungsanstall fur Viruskrankheiten der Tiere, Tübıngen, Allemagne, à I'Institut d'Elevage et de Médecine Vétérınaire des Pays Tropicaux.

(**) Notre gralıtude est acquise au personnel des Services de l'Elevage du Tchad, de lo République Centrafricaine et du Cameroun, toul spécialement à nos confrères R. FERNAGUT et J. GRATEAU, de Maroua, Nord-Cameroun, qui attirèrent notre attention sur de magnifiques cas cliniques. se caractérisait par de l'abattement et une fièvre élevée durant 3 ou 4 jours. Une sévère congestion buccale se manifestait, accompagnée de larmolement et suivie d'un épisode intestınal que sıgnalt une diarrhée noire et fétıde. Aucune mortalité ne s'ensuivait. La maladie était transmise au veau par filtrat, le virus étant supporté par les leucocytes. Très irrégulıèrement contagieuse, la maladie ne pouvait être transmise au cheval, à l'âne ou à l'élan ; par contre, les buffles domestıques réagissaient fortement tandıs que des mulets auraient falt une forme inapparente.

Mis a part ce très intéressant rapport dont on dolt être reconnaissant à BROWN et SCOTT (6) d'avoir rappelé l'existence, on est en droit de se demander sı la maladie des muqueuses a été réellement reconnue sur le continent africain, et bien différenciée d'avec la peste bovine. En effet, nı la «maladie de Djumalı» décrite, avec peu de précisions il est vral, par LAMBELIN et ECTORS (12), ni les stomatıtes érosives de MASON et NEITZ (14) ne peuvent en imposer pour elle. Elle ne paraît pas avoir été authentifiée en Egypte (11). Quant au syndrome que décrivent cliniquement fort bien OTTE et PECK (20) puis OTTE (19) on peut suspecter, en 
l'absence de toute identification de l'agent étiologique, qu'il s'agit de plusieurs affections (dont vrassemblablement la vaginite infectleuse pustuleuse) réunies sous un même vocable de «rinderpest-like disease $\gg$.

Il semblait bien pourtant que la maladie des muqueuses ou une maladie très proche devait exister en Afrique. Trop nombreuses ont été en effet les relations de «rupture d'ımmunité » après vacanation antibovipestique pour que I'on ne suspectât pas une maladie autre que la peste bovine d'en être la cause.

C'est d'ailleurs l'intérêt que présente le diagnostic différentiel de la maladie des muqueuses d'avec la peste qui a incité notre laboratoire à s'occuper de ce problème au moment où se mettait en place une campagne d'éradication de la peste dans le bassin du lac Tchad (13). La présente note ne vise qu'à présenter les résultats et l'expérience acquis en ce domaine dans le ressort territorial de notre laboratoire. II paraît préférable de les présenter sous la forme d'un exposé didactique plutôt que de les groujper selon le plan habituellement suivi par les articles scientifiques. Toutefois, nous ne manquerons point de préciser (en exergue afin de ne pas alourdir le texte) certains points des techniques qui ont été employées au cours de ces recherches.

\section{I. — MATÉRIEL ET MÉTHODES}

\section{1. - Prélèvements.}

Le matériel d'étude est soit du sang prélevé par ponction veineuse et aussitôt mélangé d̀ 10 unités d'héparine par $\mathrm{ml}$, soit des ganglıons lymphatiques récoltés sur des cadavres frais de bovins morts naturellement ou abattus. Sang et ganglions sont conservés en glace fondante jusqu'au moment de l'inoculation qui a lieu 24 heures au plus tard après le prélèvement.

En quelques circonstances, divers prélèvements sont effectués en vue de faire des coupes pour étude histo-pathologique; ils sont aussitôt immergés dans le mélange fixateur du DuboscqBrazil.

Les sérums examinés pour leur teneur en anticorps ont été prélevés sur le terrain, la plupart du temps sans précautions spéciales d'asep- sie par des équipes de vaccinateurs. A l'arrivée au laboratoire, ils sont clarifiés par centrifugation et, pour ceux destinés à être examinés en séro-neutralisation, stérilisés par filtration forcée sur des disques Millipore (*).

\section{2. - Techniques virologiques.}

a) Cultures cellulaires. Des cultures de rein d'embryon de veau sont effectuées cinsi qu'il a déjà été décrit (24). Au début ont été utilısées des cellules de première explantation qui ont été par la suite remplacées par des cellules de première subculture obtenues par décollement des cellules de première explantation par le mélange trypsine-versène.

Après l'inoculation du virus suspect ou des mélanges virus-sérums suspects, on remet en culture dans le milieu M. E. M. de Eagle contenant 10 p. 100 de sérum de poulain.

b) Mise en évidence du virus par interférence. Les premières tentatives d'isolement d'un agent cytopathogène à partir des prélèvements de ganglions lymphatiques se sont soldées par des échecs. Cela n'a rien de spécialement étonnant car on sait que peu de souches du virus se montrent cytopathogènes (10). C'est pourquol a été employé un moyen détourné inspiré du travail de GILLESPIE, MADIN et DARBY ( $($ ) et adapté de leur technique.

On utilise cellulés et milieux évoqués plus haut. Dans un premier temps, on établit une «banque » titrée d'une souche cytopathogène du virus de la maladie des muqueuses. Notre choix s'est porté sur la souche MD/M-1 originaire du Bundesforschungsanstalt für Viruskrankheiten der Tiere, Tubingen, Allemagne, qui donne en 48 d̀ 72 heures des lésions cytopathiques très nettes (5). Le titre varie de $10^{4,5}$ à plus de $10^{6} \mathrm{DCP}_{50}$ selon les lots. Le liquide de culture est récolté, réparti en flacons, congelé à $-20^{\circ} \mathrm{C}$ et conservé à cette température.

Pour mettre le virus en évidence dans un prélèvement de ganglion lymphatique, on broie une petıte partie de pulpe ganglionnaire, puis on la dilue au 1 : 100e environ en liquide de Hanks

(*) Swinny hypodermic adapter no $\times \times 30-012-00$ monté avec des disques GSWP13 et des préfiltres AP20-10. Millipore Filter Co., Issy-les-Moulineaux. 
contenant antıbiotiques et fongistatique. Une légère centrifugation débarrasse des débris.

Ce liquide sert à infecter des tubes de cellules ayant subi 3 rinçages préalables au liquide de Hanks; on adsorbe pendant 2 heures à $37{ }^{\circ} \mathrm{C}$, puis on rince, et on remet en culture dans le milieu de Eagle à 10 p. 100 de sérum de poulain. Après 3 d 4 jours à $37^{\circ} \mathrm{C}$ sur un appareil rouleur de tubes, on vide le liquide de plusieurs tubes; on rince au Hanks puis on infecte ces tubes avec $0,1 \mathrm{ml}$ de virus $\mathrm{MD} / \mathrm{M}-1$ dilué pour contenir
$1.000 \mathrm{DCP}_{50 / \mathrm{ml}}$. Après - 2 heures d'adsorption, on rince puis on remet en culture dans le milieu de Eagle à 10 p. 100 de sérum de poulain.

Des tubes de cellules de même origine sont placés en contrôle ; ils reçoivent la même quantité de virus $M D / M-1$ que les tubes auparavant traités avec les extraits de ganglions présumés virulents. Les tubes sont examinés plusieurs jours pendant une semaine. Plusieurs éventualités peuvent se manifester qui sont résumées dans le tableau 1.

TABLEAU 1. - Possibilités de diagnostic de la maladie des muqueuses par la méthode de la " résistance celluloire induite » en cultures cellulaires

\begin{tabular}{|c|c|c|c|c|}
\hline \multirow[b]{2}{*}{ Diagnostics probables } & \multicolumn{4}{|c|}{ Systèmes cellulaires } \\
\hline & $\begin{array}{l}\text { Cellules lémoins } \\
\text { non traitées }\end{array}$ & 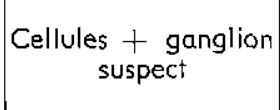 & $\begin{array}{l}\text { Cellules + } \\
\text { ganglion suspect } \\
+ \text { virus MD-Ml }\end{array}$ & $\begin{array}{l}\text { Cellules + virus } \\
\text { MD-MI }\end{array}$ \\
\hline $\begin{array}{l}\text { Possibilité de maladie des } \\
\text { muqueuses } \\
\text { (souche non cytopathogène) }\end{array}$ & Absence d'ECP (*) & Absence d'ECP & Absence d'ECP & Nécrose cellulaire \\
\hline $\begin{array}{c}\text { Possibilité } \\
\text { de peste bovine }\end{array}$ & Absence d'ECP & Plasmodes & Lyse partieile & $\begin{array}{l}\text { Lyse du } \\
\text { tapis cellulaire }\end{array}$ \\
\hline $\begin{array}{c}\text { Effet toxique } \\
\text { ou souche cytopathogène }\end{array}$ & Absence d'ECP & Nécrose & Nécrose cellulaire & Nécrose' cellulaire \\
\hline Néant & Absence d'ECP & Absence d'ECP & Nécrose cellulaire & Nécrose cellulaire \\
\hline
\end{tabular}

(*) ECP : effet cytopathique.

Cette technique présente le triple avantage de détecter les souches non cytopathogènes de virus de la maladie des muqueuses; éventuellement de détecter les souches cytopathogènes (ce qui ne fut pas entre nos mains) ; enfin de ne pas passer à côté d'un diagnostic de peste bovine.

c) Identification des virus isolés. Elle se fait par séro-neutralisation utilisant un sérum de référence.

L'antisérum est abtenu en inoculant par voie intramusculaire une génisse maintenue en étable d'isolement avec la souche MD-NY-1 du New York State Veterınary College. Elle répond par une montée thermique fugace et une leucopénie.
On la saigne 3 semaines après l'infection et l'on s'assure alors que le sérum prélevé avant l'inoculation ne neutralise pas le virus cytopathogène MD-M-1 alors que le sérum après infecfion le neutralıse (voir technique plus bas).

Pour identifier le virus, on mélange $1 \mathrm{ml}$ du liquide de culture «celiules + ganglion suspect» avec $1 \mathrm{~m}$ l de sérum; on lassse 1 heure ò $37^{\circ} \mathrm{C}$. puis on traite comme plus haut pour l'isolement en s'entourant de témoins appropriés (tableau 2). A la lecture, on apprécie la neutralisation du virus cytopathogène présent par la lyse cellularre dans les tubes correspondant aux 3 dernières colonnes de la première rangée du tableau 2. 
TABLEAU 2. - Identification d'une souche non cyfopathogène de virus de la maladie des muqueuses

\begin{tabular}{|c|c|c|c|c|c|c|}
\hline \multirow[b]{2}{*}{ Diagnostics } & \multicolumn{6}{|c|}{ Systèmes cellulaires } \\
\hline & $\begin{array}{l}\text { Cellules } \\
\text { témoins }\end{array}$ & $\underset{(*)}{\text { Cellules }}+\mathrm{IM}$ & $\begin{aligned} & \text { Cellules } \\
+ & (\mathrm{VS}+\mathrm{M})\end{aligned}$ & $\begin{array}{l}\text { Cellules } \frac{1}{1} \text { VS } \\
+ \text { virus MD-MT }\end{array}$ & $\begin{array}{c}\text { Cellules } \\
+\quad \text { NS } \frac{1}{1} \text { IM) } \\
+ \text { virus MD-M1 }\end{array}$ & $\begin{array}{c}\text { Cellules } \\
+ \text { virus MD-M1 }\end{array}$ \\
\hline $\begin{array}{l}\text { Virus Maladie } \\
\text { des muqueuses }\end{array}$ & Absence d'ECP & Absence d'ECP & Absence d'ECP & Absence d'ECP & $\begin{array}{l}\text { Nécrose } \\
\text { cellulaire }\end{array}$ & $\begin{array}{l}\text { Nécrose } \\
\text { cellulaire }\end{array}$ \\
\hline Autres virus & Absence d'ECP & Absence d'ECP & $\begin{array}{c}\text { Lyse ou ECP } \\
\text { ou rien }\end{array}$ & Lyse ou ECP & Lyse ou ECP & $\begin{array}{c}\text { Nécrose } \\
\text { cellulaire }\end{array}$ \\
\hline
\end{tabular}

(*) $I M$ : immunsérum anti-virus maladie des muqueuses ; VS : virus suspect; VS + IM : virus suspect «neutralisé » par l'immunsérum.

\section{3. - Techniques sérologiques.}

a) Précipitation-diffusion en gélose. La technique $a$ été amplement décrite pour le diagnostic de la peste bovine (23).

Pour son application au diagnostic de la maladie des muqueuses par mise en évidence d'un antigène précıpitant, II n'y avait qu'une transposition facile à faire. Mettant à profit la communauté antigénique des antigènes solubles des virus de la peste porcine et de la maladie des muqueuses signalée par DARBYSHIRE (7), l'immunsérum précıpitant connu est constitué par un sérum antisuipestique. L'antigène sous

Figure 1

DISPOSITION des REACTIFS POUT la PRÉCIPITATION DIFFUSION en GELOSE
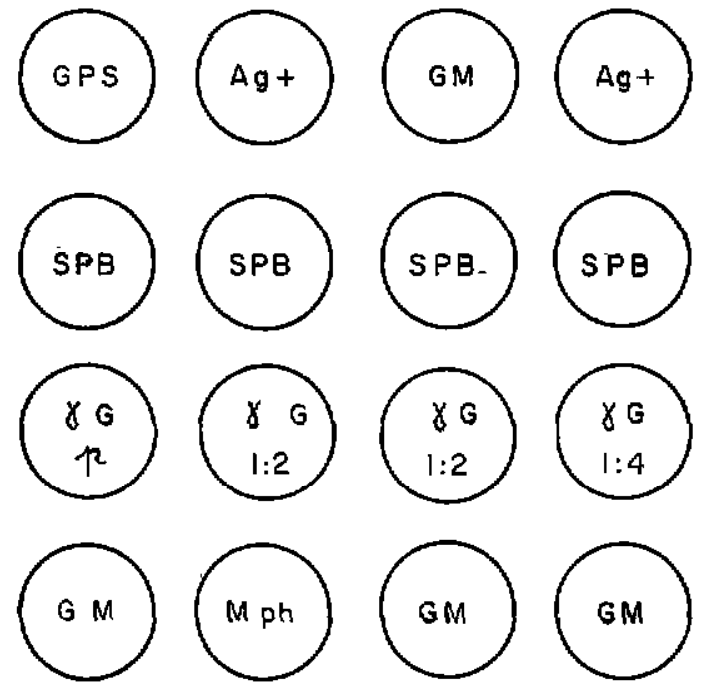

test est un broyat de tissu. En pratique, on remplace l'hyperimmunsérum antisuipestique précipitant par une gamma-globuline antisuipestique ${ }^{*}$ ) diluée au $1: 2$ et au $1: 4$ en sérum physiologique selon les indications de WACHENDÖRFER (29) pour éviter des phénomènes de zone avec des antıgènes faibles. En ce qui concerne l'antıgène, le ganglion mésentérique a été préféré au ganglion préscapulaire à l'inverse de la peste bovine. En quelques occassions on a pu utiliser les muqueuses gingivales, pharyngées, gastriques ou intestinales. La disposition adoptée est la suivante:

Les boîtes sont laissées 72 heures à $22{ }^{\circ} \mathrm{C}$ (sous un climatiseur en saison chaude au Tchad). La ligne de précipitation de la peste bovine (ou parfois les 2 lignes) apparaissent en une dizaine d'heures mais celle de la maladie des muqueuses requiert au moins une trentaine d'heures.

b) Inhibition de I'hémaggiutınation morbılleuse. Cette technique ne vient que comme

(*) Aimablement donnée par le Dr G. WACHENDÖRFER, Institut für Zoonosenforschung, J. W. Goethe Universität, Frankfurt a. M., Allemagne.
GPS = ganglion prescopulaire
$\mathrm{GM}=$ ganglion mésentérique
$M p h=$ muqueuse phoryngée
$\mathrm{Ag}=$ antigène pestique de référence
$\mathrm{SPB}=$ serum antibovipestique
$\gamma G=$ gammo globuline ontisuipestique 
appoint dans cette recherche pour rechercher les anticorps antipestiques $(3,4)$.

c) Séro-neutralisation pour la recherche des anticorps de la maladie des muqueuses. La technique suivie est celle que nous avons déjà décrite (25) en utılısant le sérum pur ainsi que le recommandent SMITH et coll. (27) pour les enquêtes sérologiques.

Un échantillon du stock de virus cytopathogène $M D / M-1$ est dilué en tampon phosphate à $\mathrm{pH}: 7,2$ (contenant par $\mathrm{ml}: 100 \mathrm{U}$ de pénicilline $100 \mu \mathrm{g}$ de streptomycine, $25 \mu \mathrm{g}$ de néomycine, $50 \mu \mathrm{g}$ de kanamycine et $2,5 \mu \mathrm{g}$ de fungizone) pour avoir $200 \mathrm{DCP}_{50 / \mathrm{mI}}$. On mélange $1 \mathrm{ml}$ des sérums à examiner avec $1 \mathrm{ml}$ du virus; on laisse incuber 1 heure à $37^{\circ}$ puis on adsorbe le mélange sur des tubes de cultures cellulaires préalablement rincées 3 fois au Hanks. Après une heure d'adsorption, on remet en culture dans le milieu de Eagle à 10 p. 100 de sérum de cheval et on place les tubes sur le tambour d'un rouleur. La lecture se fait le 4 ou 5 e jour.

\section{4. - Animaux d'expérience.}

Les bovins utilisés pour les inoculations de matériel suspect ou de ilquides de cultures cellulaires sont des bouvillons de race zébu bororo, originaires de Bouar (R. C. A.), région indemne de peste bovine depuis plus de 20 ans. Des séroneutralisations effectuées à leur arrivée au laboratoire attestent l'absence d'anticorps antibovipestiques et éventueliement d'anticorps antimaladie des muqueuses.

\section{II. - LA MALADIE NATURELLE}

Il tombe sous le sens qu'il fallait faire confiance aux cliniciens pour déceler en brousse les cas de maladie suspecte. C'est dans cet esprit que fut élaboré au laboratoire de Farcha un cours sur le diagnostic clinique et expérimental de la peste bovine (1) qui attirait l'attention sur la similitude clinique de la peste et des autres maladies bovines à tropisme digestif ou respiratoire. Cet effort devait porter ses fruits puisque dans le courant de l'année suivante notre attention était attirée sur plusieurs foyers de maladie «pestiforme » évoluant chez des bovins vaccinés contre la peste. C'est la synthèse des observa- tions effectuées par les agents des Services de l'Elevage et ceux du laboratoire qui sera rapportée dans les lignes suivantes.

\section{1. - Répartition géographique (Carte 1).}

La maladie des muqueuses a été cliniquement reconnue puis authentifiée soit par l'isolement du virus soit par la sérologie : au Tchad, en République Centrafricaine, dans le Nord-Cameroun. Il nous a été donné de la diagnostiquer à partir de prélèvements reçus de Nigeria du Nord.

\section{2. - Espèces affectées.}

La maladie n'a été observée que chez les bovins. La positivité des sérums de quelques moutons et d'espèces sauvages signe peut-être une réceptivité naturelle qu'il n'a pas été donné de rencontrer en clinique.

\section{3. - Epizootiologie sommaire.}

a) Ni le sexe ni la race ne paraissent avoir d'influence profonde. La maladie sévit avec la même infensité morbide chez des zébus bororos, arabes ou foulbés que chez des taurıns $N^{\prime}$-damas ou les croisements $\mathrm{N}^{\prime}$-dama-bororos.

b) L'âge, par contre, semble jouer un rôle. Sur environ 500 malades observés, près de $80 \mathrm{p}$. 100 ont de 1 à 3 ans ; la plupart d'entre eux ont de 14 d̀ 24 mols (veaux «dents de laits»). Quelques veaux encore à la mamelle (3 à 5 mols) peuvent néanmoins être atteints. Il a été rapporté des cas de maladie sur de plus vieux animaux (dont un bœuf de 9 ans, et une dizalne de taureaux N'dama adultes faisant partie d'un effectif de 50) ; bien que n'ayant pas observé ces cas, un fort crédit peut être apporté à ces affirmations car nous verrons, par le résultat des enquêtes sérologıques, qu'elles trouvent une explication logique.

c) Les vaccinations antérieurement pratiquées (tout au moins celles qui sont courantes en Afrique centrale : peste bovine, péripneumonie, fièvre charbonneuse, charbon symptomatique, pasteurellose) non plus que les traitements trypanocides éventuels ne parassent jouer le moindre rôle. Bıen au contraire, c'est l'antériorité d'une vaccination antrbovipestique qui a entraîné la suspıcion clınıque dans nombre de 
CARTE I

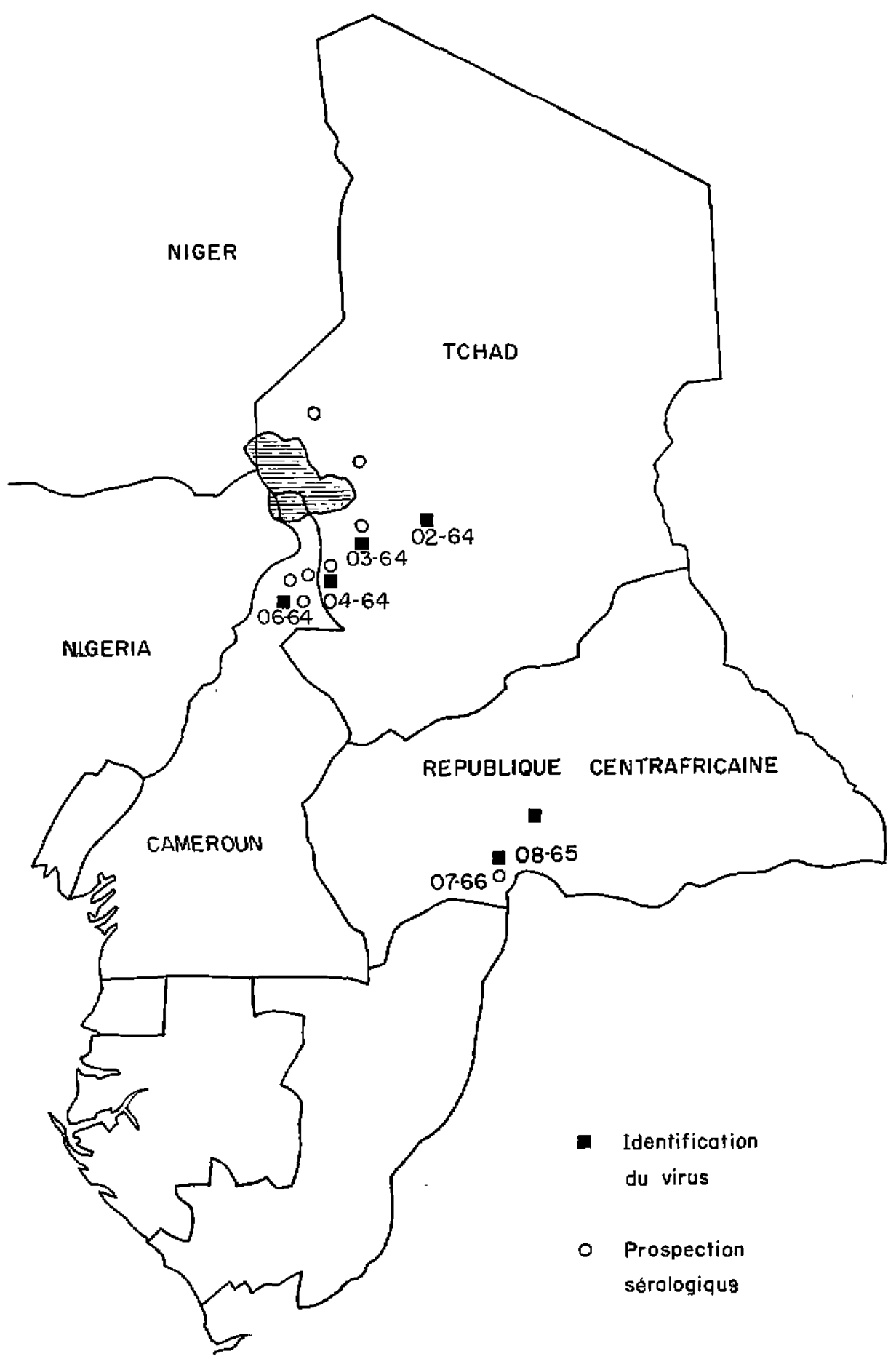


foyers rapportés (sauf 3 qui se sont produits en R. C. A. où cette vaccination n'a pas cours). Cette affirmation doit être tempérée au rappel de l'existence d'au moins 2 foyers dans lesquels coexistaient la peste et la maladie des muqueuses.

d) La saison de l'année paraît être négligeable en temps que facteur épizootiologique. Des foyers ont éclaté aussi bien en saison fraîche (décembre) qu'en saison chaude (mars) ou en saison des pluies (juin, août).

e) Conditions d'entretien. La maladie des muqueuses a été observée en élevage pastoral nomade, sédentaire villageois mais également dans des stations d'élevage sur des animaux destinés à la reproduction et particulièrement bien soignés. La gravité de la maladie ne paraît pas être influencée par l'état d'entretien, mais il est possible qu'il y ait une interaction virulence des souches - état d'entrefien qu'il n'a pas éfé donné d'apprécier. Dans un cas très particulier, c'esí juste après un transport qu'elle est apparue sur des animaux en parfait état d'entretien, originaires d'un ranch d'élevage.

f) Morbidité, mortalıté. La morbidité est variable d'un foyer à un autre, tout en se limitant, ainsi qu'il vient d'être mentionné, à la tranche d'âge de 0 à 3 ans. Dans ce groupe, le pourcentage des animaux cliniquement atteints varie d'un troupeau à l'autre, sans qu'on ait pu en discerner les causes, de 10 à 90 p. 100.

La mortalité est elle aussi variable, de 10 p. 100 des veaux malades à 50 p. 100 (vorre 90 p. 100 dans un foyer). II semble que ce n'est que lorsque la mortalité dépasse les « normes permises » que les éleveurs s'ınquiètent et viennent effectuer la déclaration. Les facteurs aggravant le taux de mortalité ne sont pas élucidés, mais il est fortement suspecté que les infestations vermineuses du début de la salson des pluies contribuent c̀ assombrir le pronostic.

Dans le cas particulier du troupeau N'dama déjà évoqué où la maladie est apparue après le transport, dix taureaux tombèrent malades et tous les dix moururent. En ces carconstances, Il est possible qu'une rupture de prémunition rickettsienne sir aggravé le cours normal de la maladie.

g) Cinétique de l'épizootie. Dans un même troupeau, la maladie se montre incontestable- ment contagieuse, mais la contagion n'est pas subtile et là encore existent de grandes variations. C'est ainsi que dans un troupeau de 137 têtes, comprenant 34 jeunes, la maladie a évolué en un mois alors que dans un autre de 260 comprenant 60 veaux, on trouvalt encore des malades 3 mois après la reconnaissance des premiers cas. Dans un troupeau d'une cinquantaine de têtes de taureaux N'dama, 10 animaux présentèrent des symptômes à 2-3 jours d'intervalle les uns des autres. Les autres restèrent en bonne santé apparente.

Il ne semble pas que la maladie prenne une allure enzootique ; tout au plus peut-on dire que son évolution est traînante.

Peu subtile dans un troupeau, la contagion entre troupeaux peut paraître encore être moindre. Il est difficile de suivre la marche de la maladie dans une région si l'on ne s'cide pas d'une carte en y mentionnant les points d'apparition chronologique des foyers. Sur le terrain luimême, la notion de transmission du contage est d'appréciation difficile; nous n'en connaissons qu'un seul exemple. Ce n'est que l'enquête sérologique qui fournit, comme on le verra, l'explication de ce caractère particulier de la contagion de la maladie des muqueuses. Nous connaissons enfin un exemple de contagion médiate par l'intermédiaire d'une embarcation ayant servi à transporter des bovins malades.

La carte 1 concrétise l'épizootiologie des foyers connus de la maladie au Tchad, en R. C. A. ef au Nord-Cameroun de 1964 à Juillet 1966.

\section{4. - Description clinique.}

Tenant compte des données qui viennent d'être exposées, il est difficile de préciser les limites de la période d'incubation.

Nous diviserons la clinique en : forme typique, forme asymptomatique.

a) Forme typique. Avec des variations individuelles, la maladie des muqueuses rencontrée en Afrique centrale se présente comme une entité clinique définie. La description qui suivra est la synthèse des observations effeciués, particulièrement celles de Gazawa, Nord-Cameroun. Nous avons renoncé à décrire plusieurs phases successives car les atteintes des différents organes ou appareils sont imbriquées dans le temps. 


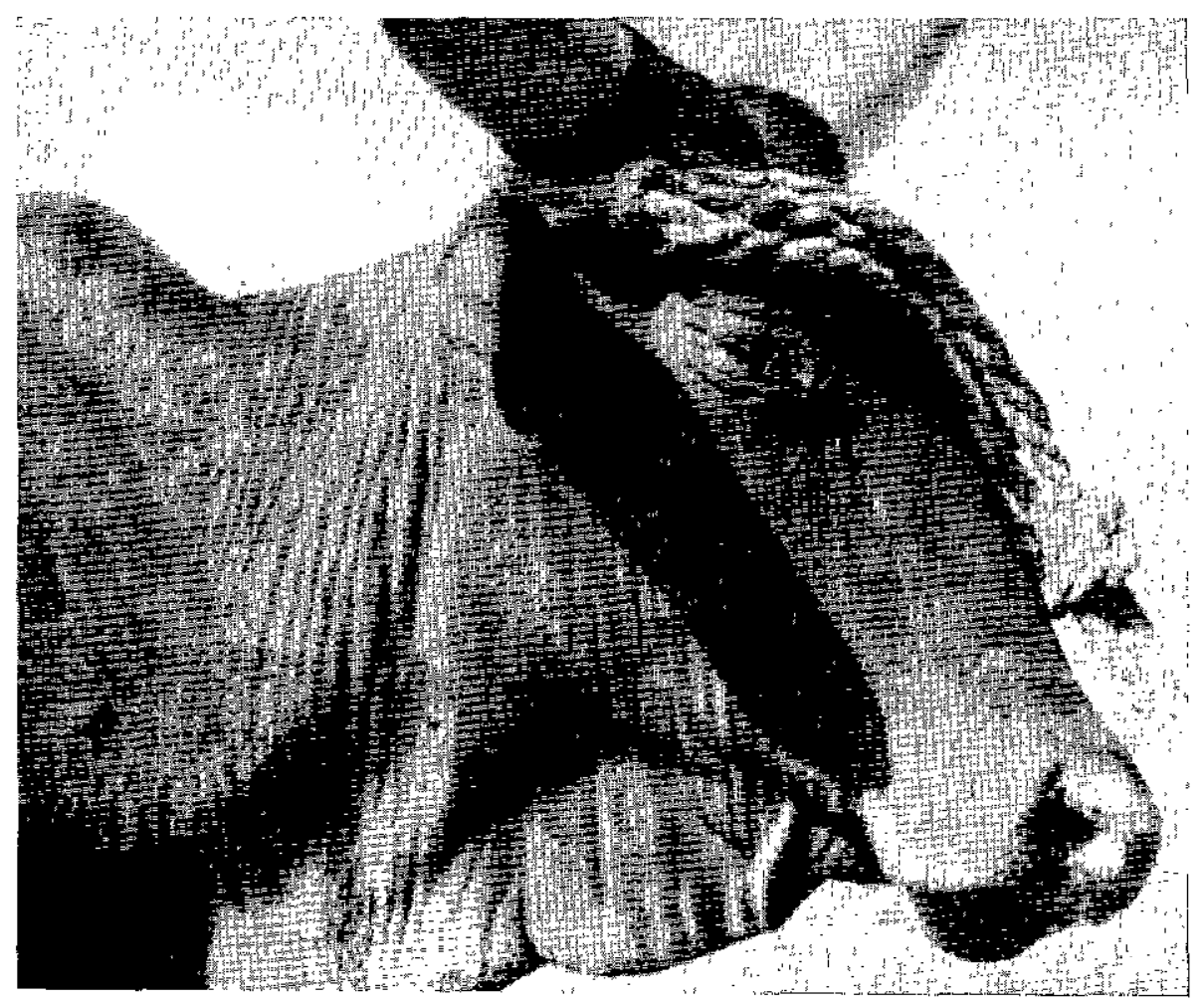

No 1. - Aspect «pestique » du bovin atteint de maladie des muqueuses.

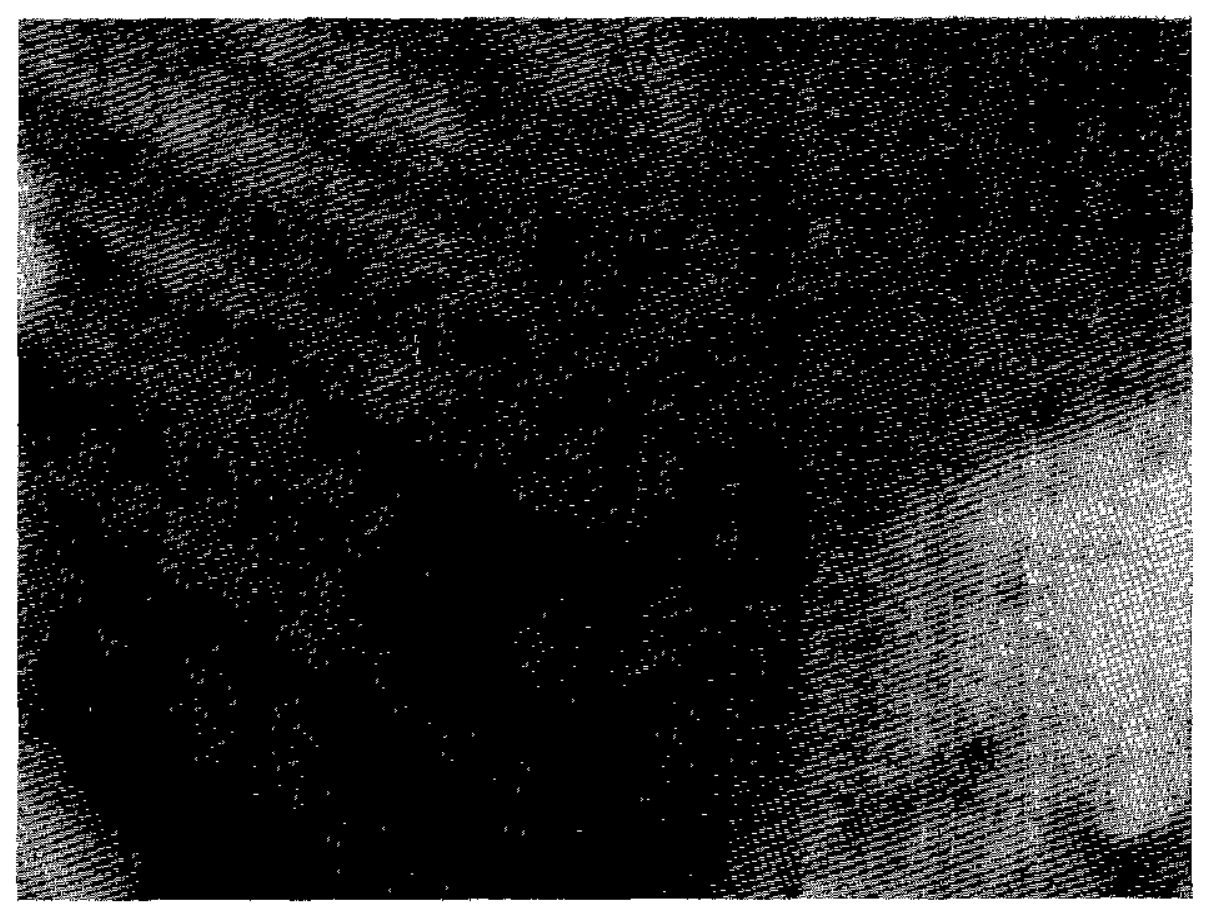

No 2. - Ulcération palałine. 


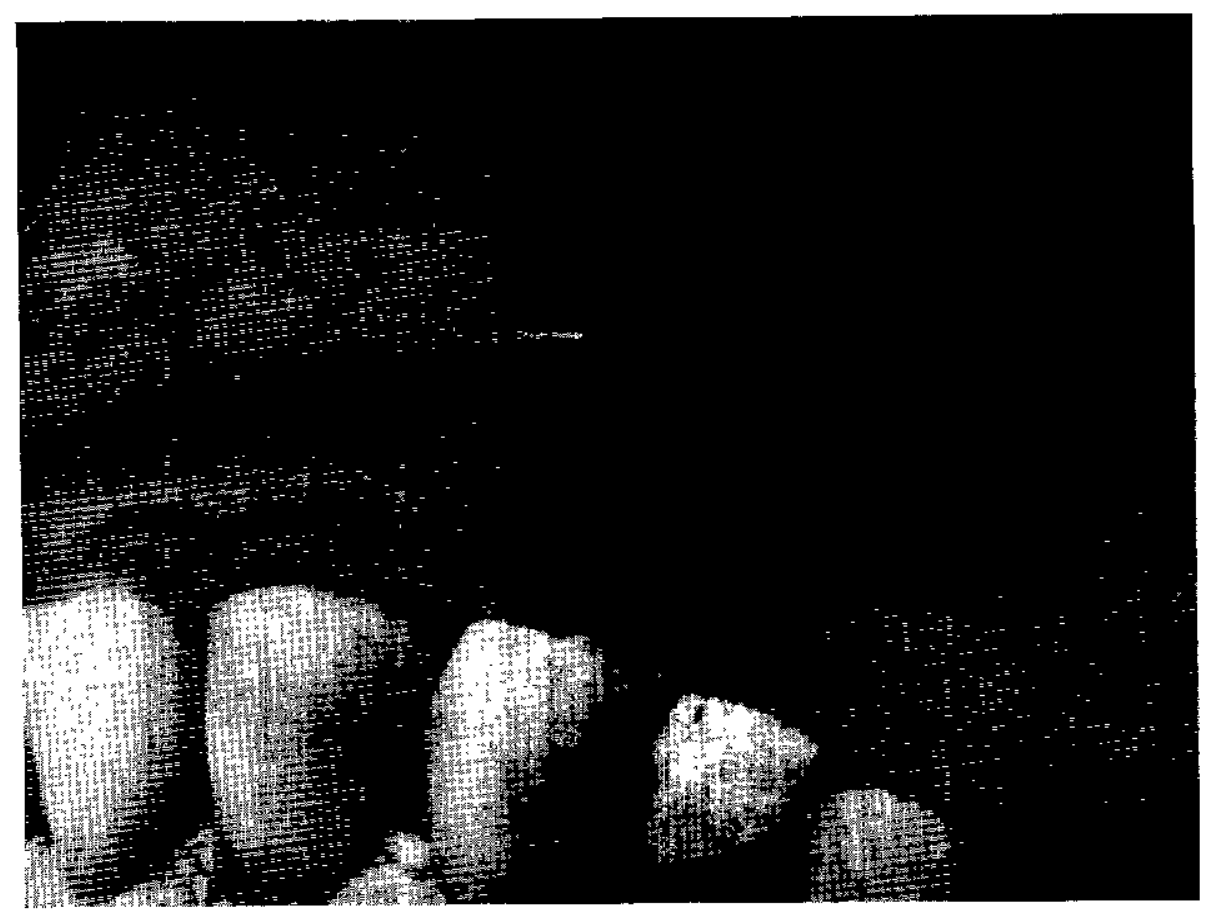

No 3. - Ulcérations du bourrelel gingival. On notera leur forme allongée. Les deux sillons situés au-dessus des incısives médianes sont traumatiques.

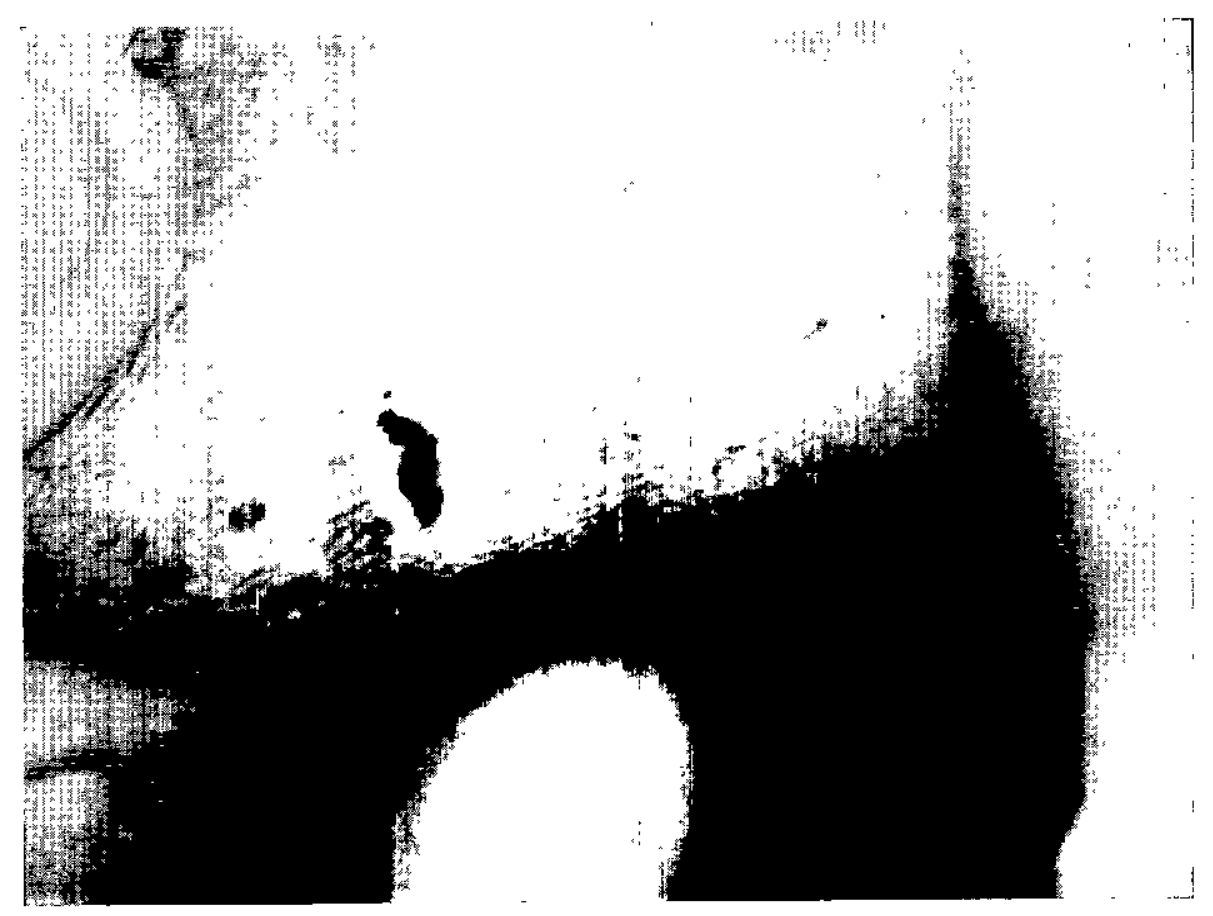

No 4. - Ulcérations de la face dorsale de la langue. 


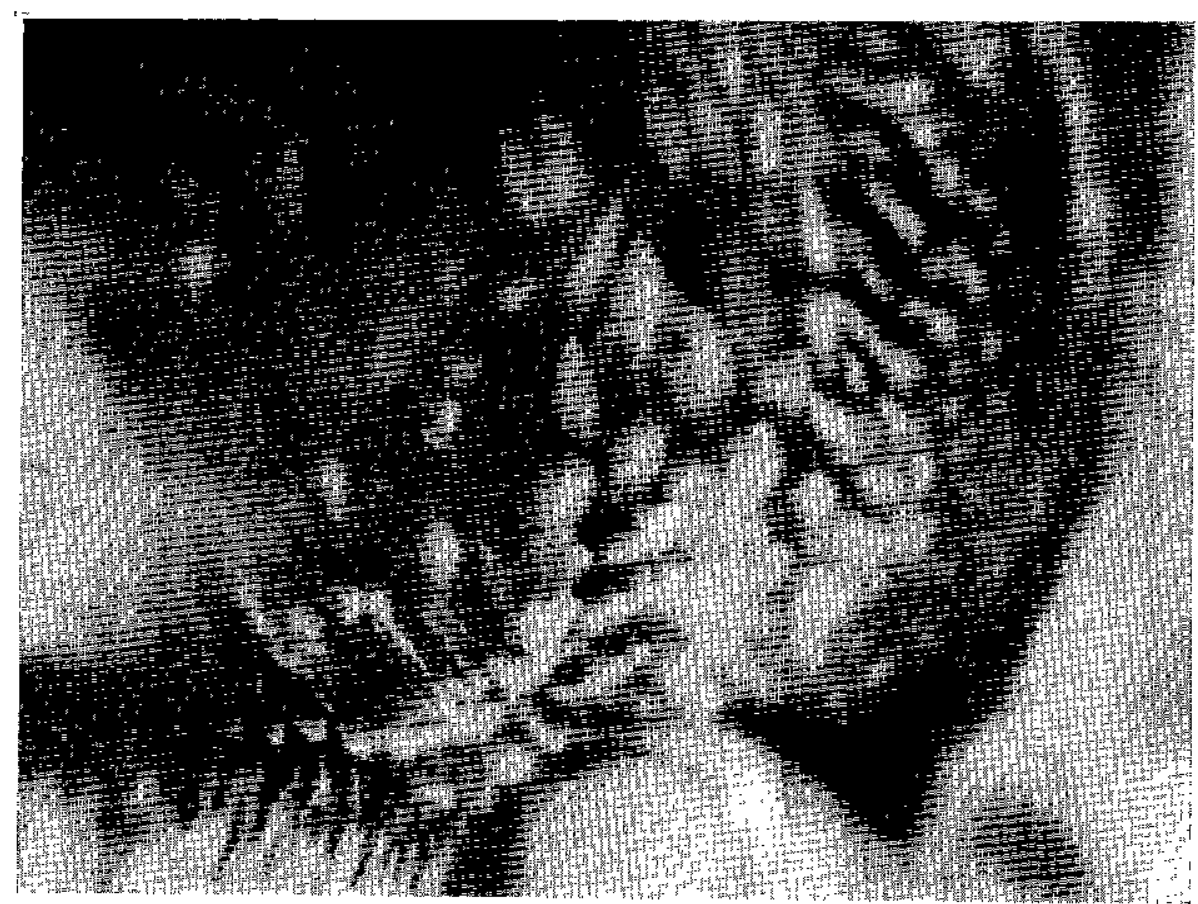

No 5. - Nécrose des papilles buccales.

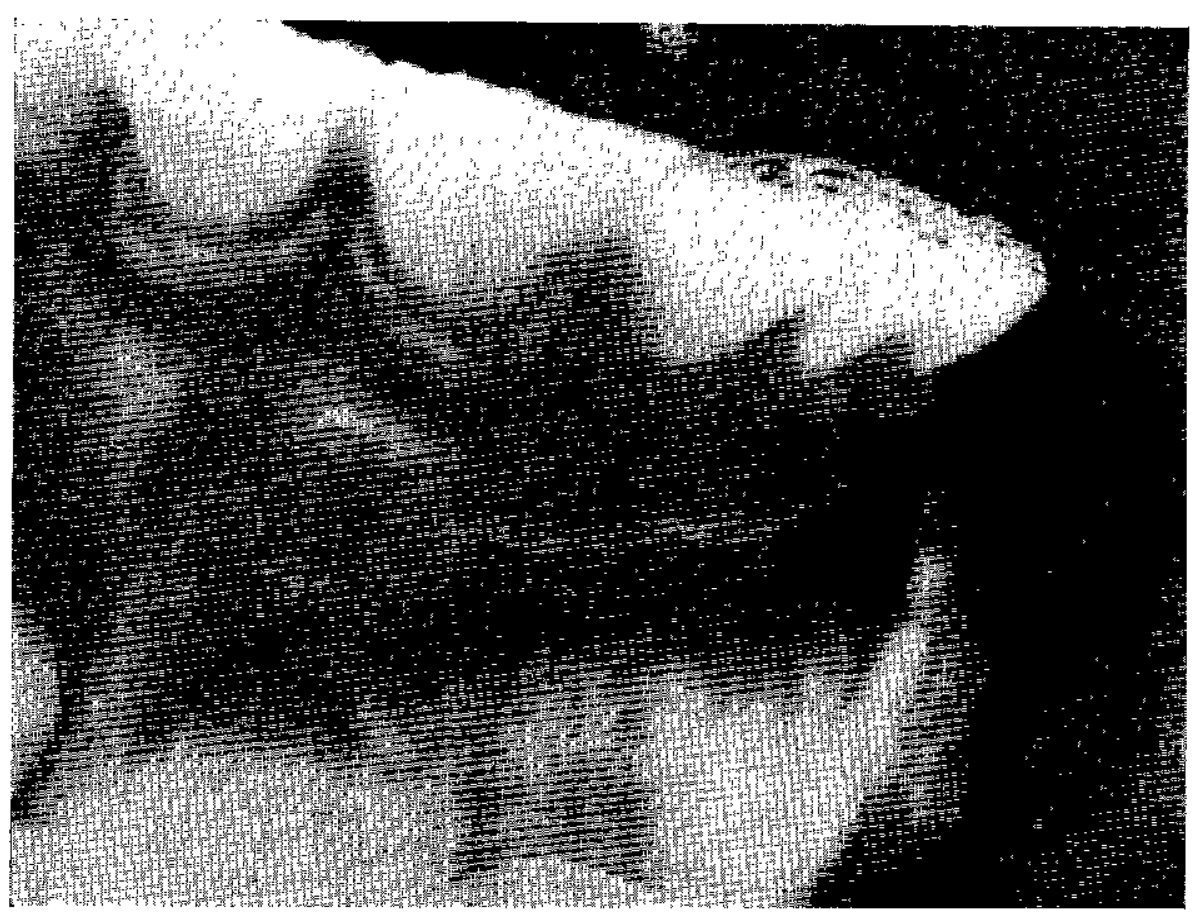

No 6. - Desquamation en nappe de l'épithélium buccal. 


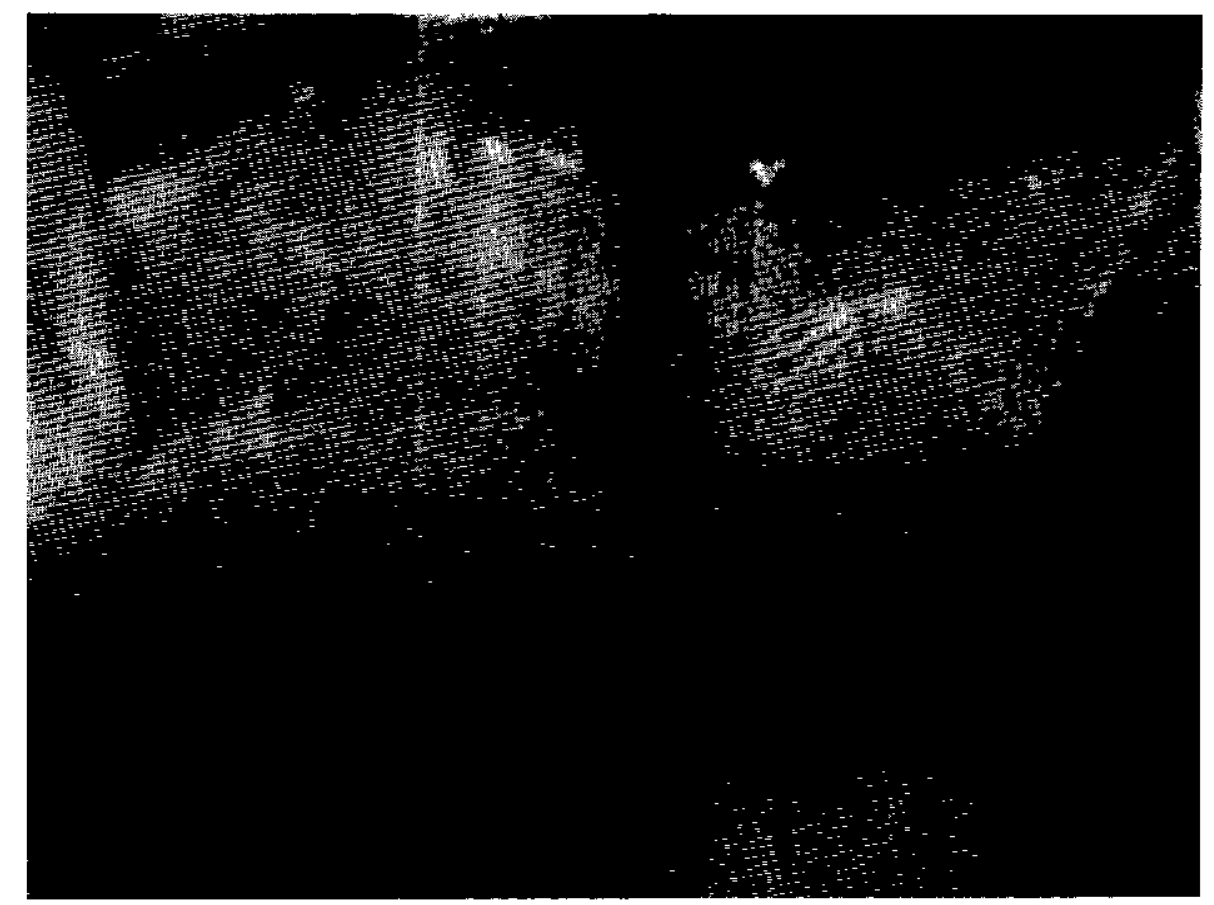

No 7. - Ulcérations en voie de cicatrisation.

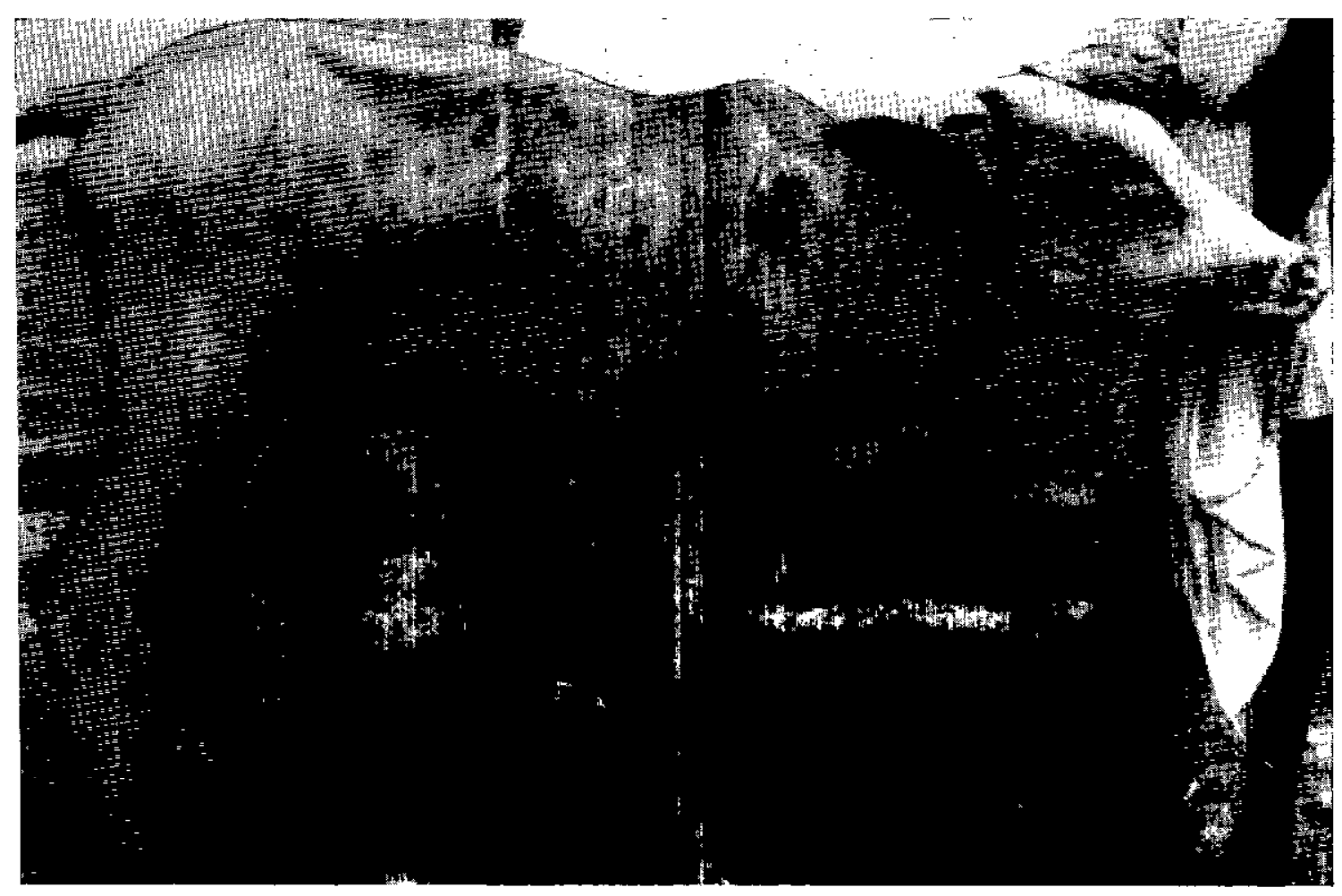

Nos 8 et 9. - Sphacèles cutanés intéressant l'épiderme. La peau apparaît cortonnée. 

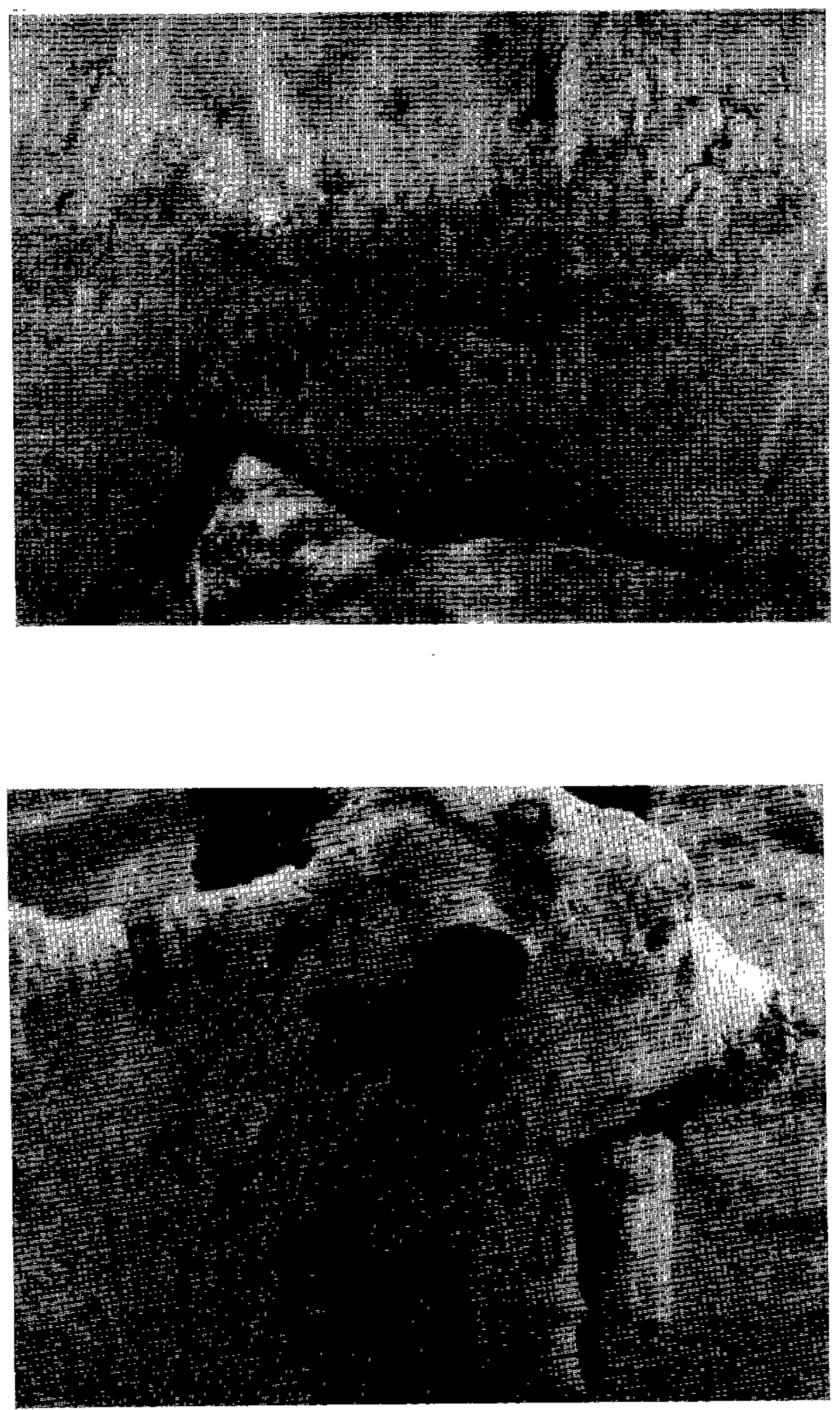

№ 10, - La peau est épaisse, gaufrée, croôteuse, spéciclement sur le cou. 


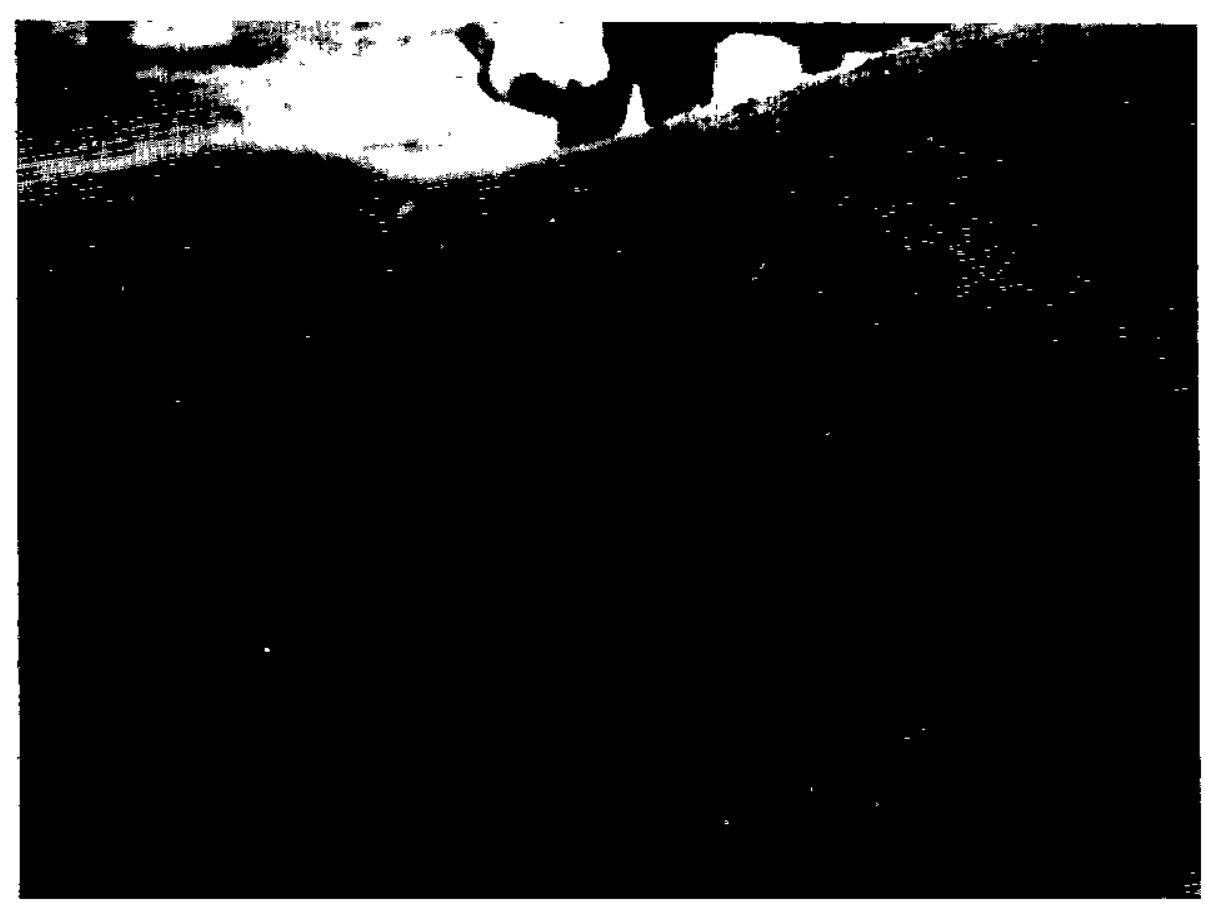

No 11. - Hérissement des poils en touffe, autre aspect de la localisation cutanée de la maladie.

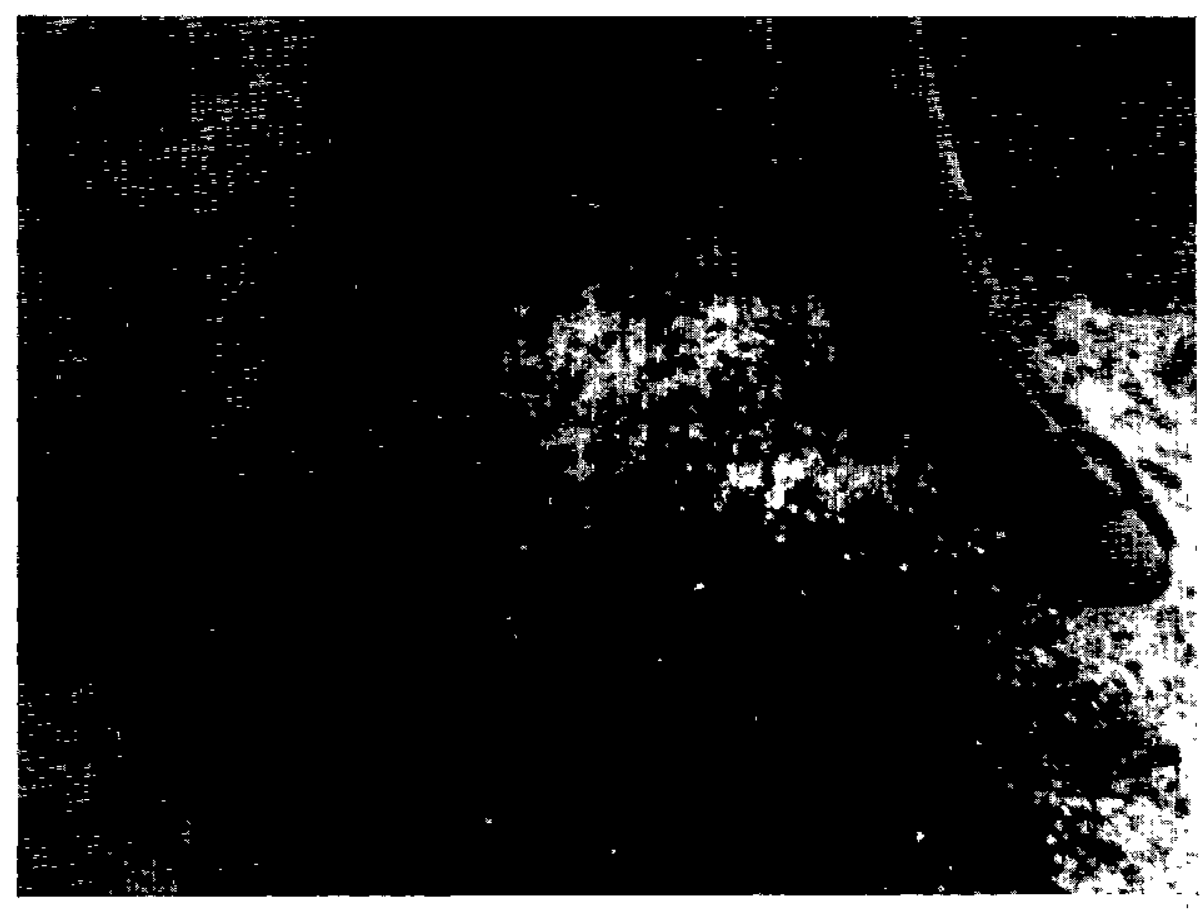

No 12. - Inflammation ef sillon nécrotique des bourrelets coronaires. 
La flèvre est le premier des symptômes. Dans un troupeau où la maladie est en évolution, on repère quelques animaux tristes, ne cherchant pas à brouter, au mufle sec. Chez eux, la température ne monte jamais très haut $\left(40,5^{\circ} \mathrm{C}\right.$ au maximum, température matinale). L'hyperthermie paraît ne pas se maintenir ; en bien des cas la température est normale lorsqu'apparaissent les autres symptômes. Les malades sont abattus, ont l'appétıt coupé. Cet état dépressif n'a toutefois rien de comparable avec l'aspect typhique d'un veau atteint de peste.

Puis apparaît une conjonctivite qui se traduit extérieu rement par du larmoiement (photo $n^{0} 1$ ). Un peu de jetage s'écoule des nasecux. Le mufle est très sec.

Des mouvements de mastication à vide et une salivation exagérée attirent l'attention vers la bouche. Les faces internes des lèvres, les gencives, le bourrelet, le palais apparaissent rose vif mais non pas très fortement congestionnés. Les muqueuses sont dépolies. Rapidement, en un à deux jours, elles se couvrent de petites taches blanchâtres; les unes sont arrondies, de 5 à $10 \mathrm{~mm}$ de diamètre, sur les lèvres, les gencives, les joues; les autres rectilignes, ceci tout spécialement sur le bourrelet, le palaıs et la face dorsale de la langue. Ces taches correspondent à des zones de nécrose de l'épithélium qui en tombant va laisser une ulcération à fond rougeâtre (photos 2 et 3).

Ces ulcérations en nombre variable, apparaissent dans toute la bouche (lèvres, palais, gencives) y compris la face dorsale de la langue (photo 4) où elles ont volontiers l'aspect de blessures transversales. Les papilles des commissures labiales ont leur partie distale érodée (photo 5). En quelques occasions, l'épithélium buccal se desquame en totalité (photo 6) laissant le chorion à nu ; cet aspect est particulièrement saisissant pour la langue qui se présente alors comme totalement pelée. L'odeur de ce tissu nécrosé est infecte.

La cicatrisation de ces ulcères buccaux se fait très rapidement. Une semaıne après leur apparition et alors qu'ont vu le jour d'autres symptômes, il ne reste plus que de petites escarres brunâtres circonscrits par un bourrelet inflammatoire (photo 7). Un examen tardif des malades pourrcit conduire à la méconnaissance d'une phase buccale. Sur la langue, le fond de l'ulcère devient noirâtre et la cicatrisation paraît se faire comme sous-crustacée.

En quelques circonstances, on remarque de petıts ulcères de la muqueuse des nasecux. Nous avons noté un cas de kératite unilatérale.

En même temps qu'évoluent ces ulcérations buccales, le mufle se fendille; les fentes se réunissent en un réseau enserrant des territoires qui se sphacèlent en surface et finissent par donner de larges surfaces ulcérées de la surface du mufle.

Concomitante de cette localisation à prédominance muqueuse de la maladie, évolue une locaIisation cutanée. Elle semble revêtir une particulière importance lorsqu'elle existe, tant par son intensité symptômatologique que par sa précocité d'apparition dans la chronologie des symptômes. Il est bon de souligner que ce n'est pas dans tous les foyers que l'on peut observer ces localısations cutanées. Elles paraissent de prime abord être associées à une forte morbidité et évolver surtout sur des bouvillons.

Dans les formes graves, ce sont d'abord de petits hérissements des poils qui attirent l'attention ; Ils sont localisés sur l'encolure et sur le dos.

A l'examen, on voit la base des poils agglutinés en touffe par une sérosité très rapidement desséchée. En saisissant la touffe ou en voulant gratter avec l'ongle, le toupillon et l'épiderme se séparent du reste de la peau, lasssant le derme scignotant d̀ nu. Rapidement, en 1 à 2 jours, de larges sphacèles cutanés se produisent d'euxmêmes (photos 8 ef 9); le derme apparaît rosé ou rougeatre. L'a peau alentour se cartone, devient épaisse, gaufrée, croûteuse, alopécique sur des régions entières, tout spécialement sur le cou (photo 10). Là encore, fait surprenant, la cicatrisation se fait très rapidement, mals les endroits où l'épıderme s'est restauré sont dépıgmentés et glabres. II semblerait pourtant que les poils finissent par repousser.

En maintes occasions, l'évolution n'est pas aussi spectaculaire que celle qui vient d'être décrite. On ne note que de petites touffes de poils hérissées suriles épaules, le dos et les flancs. Tout rentre danș l'ordre en quelques jours (photo 11).

Chez certains animaux on note une inflammation et des ulcérations du bourrelet coronaire (photo 12) qui entraîne une douleur podale ef des piétinements. Cette «danse sur place» de quelques individus dans un troupeau de malades 
attire l'attention car on ne la voit pas dans la peste bovine.

Ce n'est qu'après plusieurs jours d'évolution des symptômes cutanéo-muqueux (en moyenne 3 à 4 jours) qu'apparaît la diarrhée. Elle n'est pas constante. Lorsqu'elle existe, elle est souvent intense, parfois discrète. Elle ne dure que quelques jours et cesse en général en même temps que cicatrisent les lésions buccales. Ses caractères sont particuliers : très fluide, brun noirâtre, elle jaillit sans souiller l'arrière-train du malade. Elle ne contient pas de sang en nature mais en se désséchant devient noire. Ce caractère très particulier la différencie de la diarrhée de la peste bovine. Cette couleur noire a valu à la maladie que nous décrivons son nom arabe de : «am biténé zarga », la maladie du ventre noir, que les éleveurs avisés savent parfaitement différencier de la peste bovine.

Les émıssions diarrhéiques sont plus fréquentes au début qu'au décours de la maladie.

Au total, l'évolution de la maladie des muqueuses observée en Afrique centrale dure de 8 à 15 jours. La guérison s'annonce par la reprise de l'appétıt, la cicatrisation des ulcères et des délabrements cutanés, ef la cessation de la diarrhée.

La figure 2 tente de retracer l'enchaînement de l'évolution des différents symptômes.

Figure 11

EVOLUTION des SYMPTOMES dans la MALADIE

des

MUQUEUSES, NATURELLE ef EXPERIMENTALE
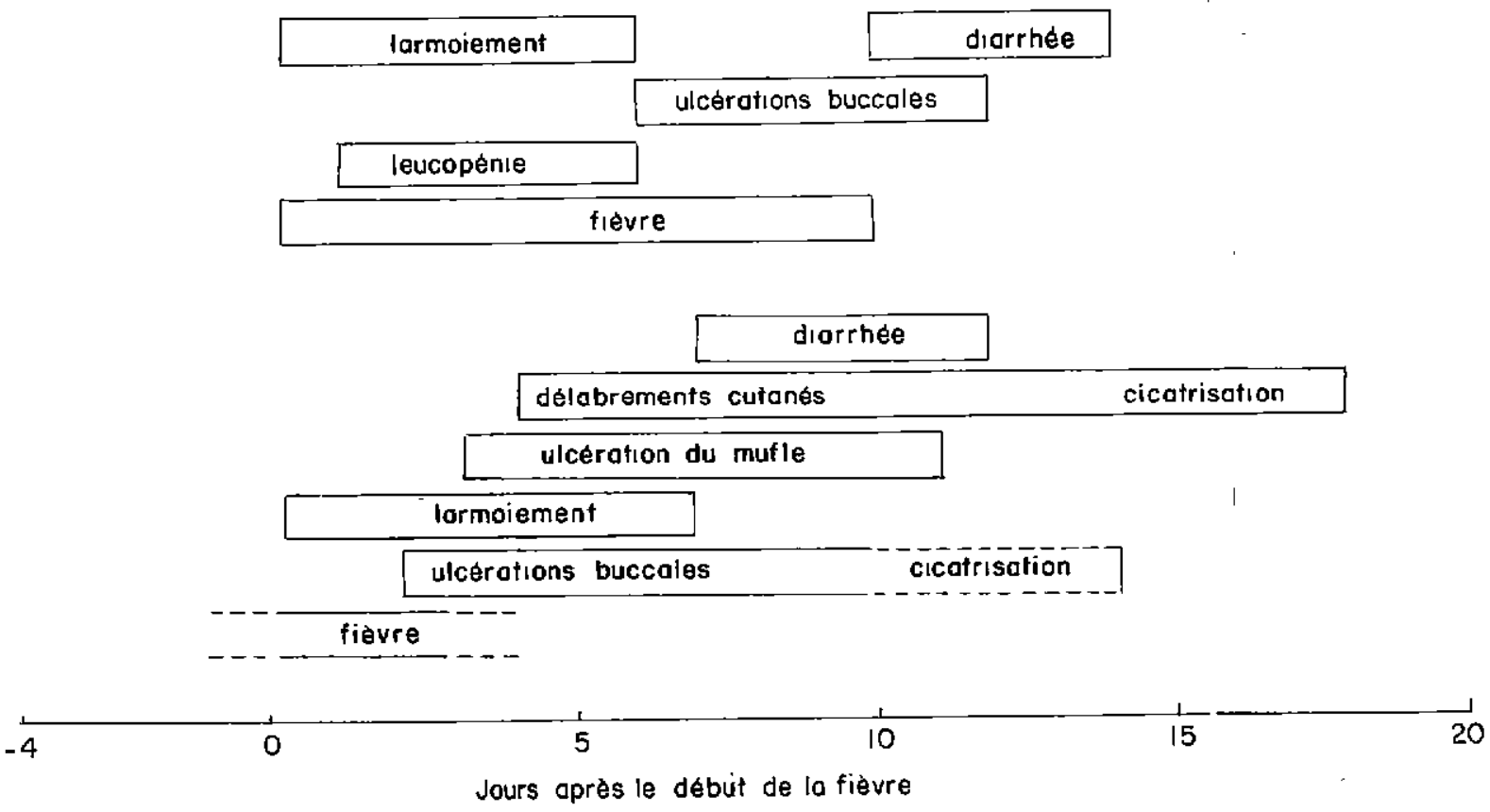
b) Formes asymptômatiques, II esł vraisemblable qu'elles sont extrêmement fréquentes étant donné la proportion de bovins ayant une sérologe positive et la rareté de la maladie cliniquement déclarée. Les épisodes diarrhérques frustes ou les stomatiques d'apparence banale que I'on note en maintes circonstances chez des veaux ne sont peut-être que la traduction à bas bruit de l'infection par le virus.

\section{5. - Lésions.}

En dehors des lésions cutanées ci-dessus évoquées, le cadavre d'un bovin mort de maladie des muqueuses présente surtout des lésıons digestives.

10 Appareil digestif :

- Mufle sec, fendıllé, ulcéré avec des sphacèles plus ou moins grands mais pouvant atterndre la totalité du mufle.

- Congestion buccale modérée. Ulcérations à fond rougeâtre, à bords d̀ pic, irrégulières, couvertes d'un enduit pultacé blanchâtre d'odeur désagréable, ou bien à fond noirâtre d'aspect $\mathrm{sec}$, corné, lorsque la maladie a évolué depuis un certain temps.

Ces ulcérations siègent dans toute la bouche et sur le voile du palais. Elles sont très marquées sur le palais. Parfois on observe une nécrose en nappe de l'épithélium buccal. cales.

- Nécrose de l'extrémité des papilles buc-

- Lésions des faces ventrales et dorsales de la langue: sur la face ventrale ce sont des ulcérations arrondies; sur la face dorsale, ce sont des tranchées ulcérées perpendiculaires au grand axe de l'organe ainsi qu'une nécrose de l'extrémité des papilles. Parfois toute la muqueuse est nécrosée.

- Dans le pharynx, se trouvent les mêmes ulcérations que dans la bouche. Dans l'osophage, c'est plus spécialement dans la partie cardiaque que l'on en trouve; elles sont aliongées selon le grand axe, en coup d'ongle.

- Les grands réservoirs digestifs ne montrent que de larges surfaces de muqueuse érodée sur les piliers du rumen. Le chorion ne paraît pas être partıculièrement congestionné. La caillette, par contre, ressemble à celle rencontrée dans la peste bovine : congestionnée surtout sur les replis pyloriques, œdémateuse, parsemée dans le fundus de nombreux petits ulcères à l'emportepièce, laissant aussi la place à de très larges ulcérations.

- L'absence de lésions du début de l'intestin grêle, contraste avec celles de la caillette. Ce n'est pas avant l'iléum et la valvule iléo-coecale que l'on remarque des plaques de congestion, vorre des ulcérations. Les plis du coecum sont congestionnés, parsemés d'un piqueté noirâtre.

- Le gros intestın et le rectum sont congestionnés, avec ça et là des zébrures noirâtres et non pas hémarragiques. On a plus l'impression d'un semis de points noirs sur les plis du rectum que de lésions hémorragiques.

$2^{\circ}$ Ganglions lymphatiques:

Ils sont hypertrophiés, succulents à la coupe. Assez curieusement, les plaques de Peyer de l'intestin ne parcissent pas être particulièrement touchées.

3o Autres organes et appareils :

Rien à signaler.

\section{6. - Diagnostic.}

a) Diggnostic clinique :

Il faut avouer qu'il est, en Afrique centrale, extrêmement difficile de poser avec certitude un diagnostic de maladie des muqueuses basé sur les seules données épizootiologiques, cliniques et nécropsiques.

En faveur de la maladie des muqueuses, on retiendra :

- sur le plan épizootiologique, l'antériorité d'une ou de plusieurs vaccinations antipestıques effectuées dans de bonnes conditions (âge de l'animal, conservation du vaccin);

- sur le plan clinique :

la brièveté de la fièvre,

la dépression modérée,

le peu de tendance à l'extension des ulcérations buccales, leur cicatrisation ropide, le fond noirâtre des ulcérations en voie de cicatrisation,

le nécrose de l'extrémité distale des papilles commissurales,

les lésions du dos de la langue, 
les chutes de poil, l'aspect cartonné du revêtement cutané ; la concomitance de ces lésions avec l'évolution des uicérations buccales,

les caractères de la diarrhée, en particulier sa couleur noire,

l'inflammation du bourrelet coranaire entraînant la boîterie :

- sur le plan nécropsique, il est bien difficile de se fare une opinion en dehors des caractères des lésions buccales déjà évaquées et de l'absence d'une rectıte authentiquement hémorragiques.

Diagnostic différentiel. On mesure combien sur ces bases reste délıcat le diagnostıc différentiel d'avec la peste bovine, tout spécialement dans ses formes atypiques si fréquentes en Afrique centrale. A la suite de MAURER (15), on a été tenté de penser que les lésions de la face dorsale de la langue n'existaient pas dans la peste. Nous avons pu nous convaincre de l'erreur de cette proposition, tout au moins au Tchad et dans le Nord-Cameroun; par ailleurs, PLOWRIGHT (21) vient de publier de magnifiques photos de telles lésions pestiques du dos de la langue observées au Kénya. Lors de la période de cicatrisation des lésions buccales, le fond noiràtre et $\mathrm{sec}$ des ulcères plaide fortement en faveur de la maladie des muqueuses.

II semblerait que ce soient les lésions cutanées podales et surtout la couleur noire de la diarrhée desséchée qui, en Afrique centrale, seralent les meilleurs éléments du diagnostıc différentıel Iorsqu'on les replace dans le contexte complet.

II ne faut pourtant pas oublier que la peste bovine peut, dans les épizooties peu graves, donner des lésions cutanées comparées à l'échauboulure par MORNET et GUERRET (17), et accompagnées de chutes de poils. Toutefois, le derme ne paraît pas être mis à vif et la peau ne présente pas d'aspect cartonné et gaufré comme dans la maladie des muqueuses. Enfin il he faudra pas confondre les sphacèles cutanés avec les lésions de photosensibilisation dues aux trypanocides à base de dimidıum.

A notre confusion, il faut avouer qu'en absence des lésions cutanées ou podales, nous nous sommes trompés dans plus de la moitié des cas, étiquetant peste ce qui s'avérait être ensuite la maladie des muqueuses et vice-versa.
Le diagnostic différentiel est particulièrement malaisé sur les veaux; bien que non vaccinés contre la peste bovine, ils présentent souvent des formes atypiques de cette maladie.

En dehors de la peste bovine, il ne nous paraît pas qu'en Afrique centrale on puisse confondre la maladie des muqueuses avec une autre maladie.

\section{b) Diagnostic expérimental.}

Etant donné l'Incertitude qui règne sur le diagnostic clınique, on comprend toute l'importance que revêf le dıagnostic expérımental, autant pour identifier la maladie suspecte que pour décider des mesures à prendre.

Les buts du diagnostic expérımental viseront essentiellement à mettre en évıdence le virus ou ses antigènes, accessoirement à asseoir le diagnostic par la constatation d'une montée d'anticorps spécifiques chez les convalescents.

La qualité des prélèvements s'avère donc être de toute première importance. On s'adressera :

Pour la recherche du virus : à du sang hépariné, verséné, ou à défaut citraté ; à des fragments de rate; aux ganglions lymphatiques (rétro-pharyngiens, mésentériques, coliques).

- Pour la recherche de l'antigène précipitant : aux ganglions rétro-pharyngiens, à la muqueuse pharyngée, gasłrique ou intestinale, débarrassée au maximum du chorion sousjacent.

- Pour la recherche des anticorps, à 2 prélèvements de sérum effectués à une quinzaine de jours d'intervalle.

Tous ces prélc̀vements doivent évidemment être faits avec le maximum de précautions de stérilité et voyager sous froid.

Les prélèvements sont traités ainsi qu'il a été dit plus hout.

Dans ces conditıons, if nous a été donné d'isoler 3 souches de virus, toutes trois non cytopathogènes pour les cultures cellulaires de rein d'embryon de veau.

L'antigène précipitant a été mis en évidence 6 fois par précipitation en gélose.

Le diagnostic a été posé une fors par recherche des anticorps neutralisants. 


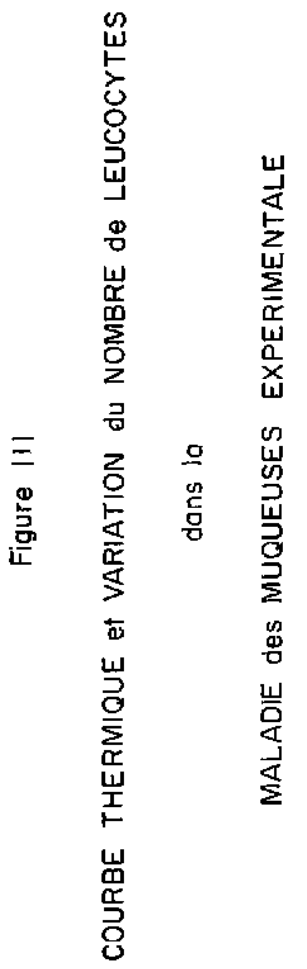

$\begin{array}{lllll}0 & 0 & 0 & 8 & 0 \\ 0 & 8 & 0 & 8 & 8 \\ 0 & 0 & 0 & 0 & 0 \\ 0 & \infty & 0 & 0 & \text { N }\end{array}$
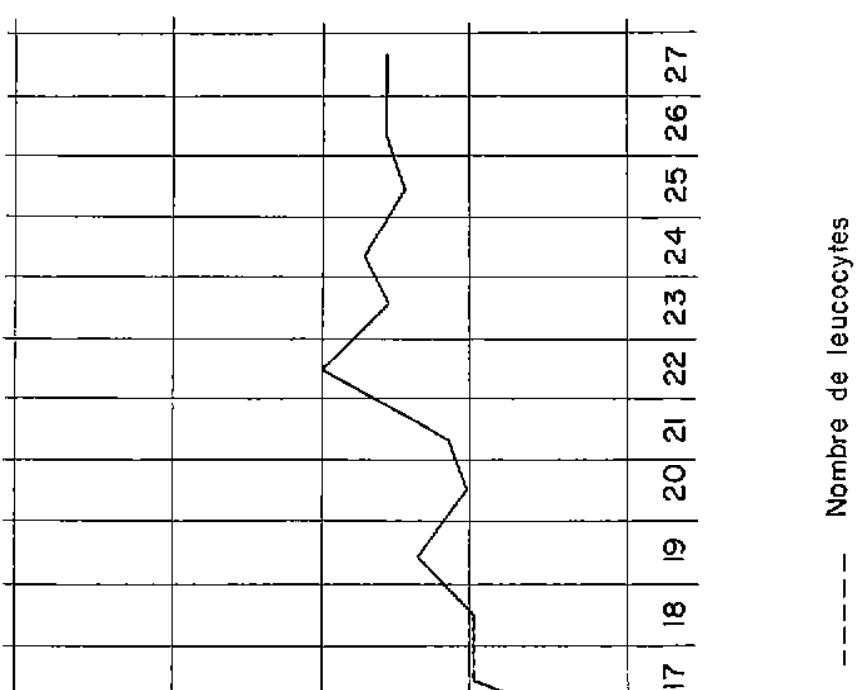

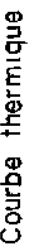




\section{III. - LA MALADIE EXPÉRIMENTALE}

Au début où ces recherches étalent entreprises, il était important de faire la distınction entre la peste bovine ef la maladie des muqueuses; nous n'avions pas alors encore en main le procédé d'identification du virus en cultures cellulaires décrif plus haut et force a été de recourir à l'inoculation de bovins vaccinés ou non contre la peste pour tenter d'assear le diagnostic.

L'origine des bovins réceptıfs à lo peste bovine et, pour autant que soit valable le test de séroneutralisation, à la maladie des muqueuses, a déjà été décrite.

L'inoculation intraverneuse et sous-cutanée de sang héparmé d'un malade atteint d'une maladie « muqueuse » reproduit un tableau clinique saisissant :

- après une incubation de 4 jours, fièvre avec courbe diphasique étalée sur 10 jours (fig. 3);

- leucopénie intervenant entre les deux pics hyperthermiques ;

- reproduction d'une grande partie de la symptomatologie de la maladie naturelle avec larmoiement, congestion des muqueuses de la tête, uicérations gıngivo-glosso-palatines, piétinement sur place traduisant l'inflammation podale, puis finalement diarrhée.

Le décours de la maladie expérimentale s'amorce vers le $12 \mathrm{e}$ jour, débutant par la cicatrisation des ulcères puis la cessation de la diarrhée. Aucun veau inoculé n'est mort.

On a pu noter dans la maladie expérimentale un ensemble de symptômes qui n'avalt pas été vus dans la maladie naturelle : la chaleur exagérée des cornes, leur grande sensibilité, la mobilité de l'étui corné qui peut être tourné de près de $1 / 8$ de tour. Apparaissant le $5-6^{\mathrm{e}}$ jour de la maladie, ces signes disparassent vers le $10^{\mathbf{e}}$.

Par contre aucun veau inoculé n'a présenté de lésıons cutanées. Tout au plus a-t-on pu voir sur l'un d'eux un hérissement de petıtes touffes de poils sur la ligne du dos et les côtes, mass qui a très vite rétrocédé sans dépilations ni chute du derme. On trouvera sur la figure 2 une tentative de comparaison de l'évolution de la maladie naturelle et de la maladie expérımentale.

\section{IV. - ENQUÊTE SÉROLOGIQUE}

Il étaıt intéressant de voir quelle pouvait être l'extension de l'infection. A cet effet, a été réclisé un sondage sur des sérums envoyés au laboratoire. Pour des raisons techniques tenant à la conservation des sérums à $-20 \circ \mathrm{C}$, n'ont pu être examinés que des sérums du Nord-Cameroun et de l'Ouest tchadien.

La technıque de séro-neutralısation vtilisée o été décrite plus haut.

Au Nard-Cameroun, sur 102 sérums de bovins adultes, 81 (soit 79,4 p. 100) ont des anticorps.

Par contre, parmi les sérums des jeunes bovins âgés de 7 à 24 mois, seuis 17 sur 146 (soit 11,6 p. 100 ) en hébergent. II est bon d'ailleurs de faire remarquer que sur les 17 sérums positifs, 14 proviennent d'un village où la maladie des muqueuses a sévi en 1964. Sur les veaux âgés de 1 à 4 mois, on trouve 80 p. 100 de sérums positifs (48 sur 60 examinés).

Dans l'Ouest tchadien, les chıffres sont les suivants : 56 sérums d'adultes sur 74 (soif 75,6 p. 100) sont positifs. Jusqu'à l'âge de 2 ans, onze sérums de veaux sur 27 examinés ont été trouvés positifs, soit 40,7 p. 100 , mais ce chiffre tombe à 15 p. 100 quand on prend la classe d'âge de 7 mois à 2 ans. Toutefois, dans un autre groupe de bouvillons de 14 à 18 mois, achetés sur un même marché, on en trouve 79 p. 100 (19 sur 24) qui possèdent des anticorps.

Dans ce contexte, Il est intéressant de noter que 5 sérums de moutons sur 38 examinés, soit 13 p. 100, sont positifs. Enfin, on a pu trouver des anticorps chez le buffle (Syncerus coffer aequinoxiolis), le bubale (Alcelophus lelwel), le cob des roseaux (Redunca redunca) ef la gazelle (Gazello ruffifrons).

Les chiffres ci-dessus rapportés sont singulièrement plus élevés que ceux trouvés en Amérique du Nord $(10,27)$ pour les troupeaux de bovins laitiers (20 p. 100) ; par contre, ils sont concordant avec ceux observés sur les bovins de ranchıng (18) de l'Oklahoma, de l'lowa ou du Nebraska (de 65 à 90 p. 100), et sur ceux d'Allemagne du Nord (5) et du Danemark (16) où évoluent des poussées de maladie des muqueuses. Par aılleurs l'un de nous a déjà signalé la présence d'anticorps dans les sérums de moutons (2). 
Dans les résultats de ces séro-neutralisations, le contraste est sassissant entre d'une part le groupe formé par les adultes et les veaux de lait, d'autre part par les bouvillons.

En ce qui concerne les veaux de lait, il y a tout lieu de penser que leur état immunitarre reflète celui de leurs mères par immunisation colostrale passive. Les anticorps passivement transmis disparaissent vers l'âge de 6 mois. On trouve alors de jeunes bovins qui sont réceptifs à une attaque de maladie des muqueuses. L'importance des bouvillons sans anticorps (140 sur 159) semble indiquer qu'ils n'ont encore eu cucun contact avec le virus alors que les adultes des mêmes troupeaux ont déjà connu cette expérience (137 sur 158). La conversion sérologique semble donc devoir s'opérer brusquement dans le jeune âge adulte.

Une explication à apporter à cet état de choses, est de penser que la maladie des muqueuses évolue par vagues épizootiques à faible pouvoir d'extension. Les bouvillons touchés par la vague au bien extériorisent une maladie des muqueuses clinıque, ou bien ne subissent qu'une attaque à bas bruit qui n'entraine aucun symptôme morbide.

Cette manière de voir rend compte par exemple qu'un groupe de 19 bouvillons sur 24 possèdent des anticorps alors que dans le groupe témoin on n'en peut montrer que 2 sur 13 ; le premier groupe a été touché alors que le second ne l'a pas été ; ainsi s'explique aussi que 80 p. 100 des adultes conservent la trace sérique de leur contact avec le virus. II n'en reste pas moins que quelques jeunes bovins doivent échapper à la contagion, he sont contaminés que dans l'âge adulte, et font alors les maladies des muqueuses de gravité varıable que l'on rencontre dans la pratique.

L'exemple du village de Gazawa au NordCameroun paraît être particulièrement probant de la thèse soutenue. Ce village a connu en mai et juin 1964 une flambée de maladie des muqueuses touchant une majorité de jeunes et quelques adultes. Les jeunes sont salgnés 15 jours après la guérison des derniers cas, les bovins adultes 3 mols plus tard. On a dans le premier groupe : des nouvecu-nés de mères immunes; des bouvillons nés peu avant ou pendant l'épizootie; des bouvillons qui en 1964 avaient environ 1 an.
La situation immunologique au regard de ce qui nous occupe est la suivante:

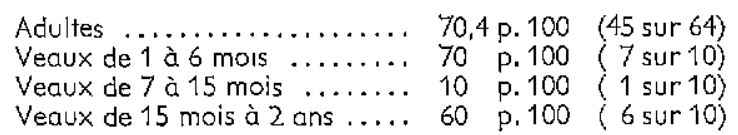

Cetfe conception épizootiologique explique aussi que la maladie des muqueuses ait pu être confondue avec la peste : quasi identiques dans leurs manifestations cliniques et leur anatomie pathologique macroscopique, les deux viroses se ressemblent encore par leur évolution sur le terrain, procedant par vagues auxquelles paient tribut les veaux sevrés et les jeunes bouvillons. La maladie des muqueuses en Afrique centrale paraît toutefors singulièrement moins contagieuse que la peste et ne peut guère être «suivie à la trace » comme cette dernière.

\section{V. - COMMENTAIRES}

On aura pu mesurer tout au long de ces lignes, la somme d'inconnues, d'incertitude voire de contradictions qu'apporte la reconnaissance de la maladie des muqueuses dans la pathologie bovine de l'Afrique centrale. La démonstration de son existence étant faite sur les plans cliniques, virologiques et sérologiques, elle appelle quelques commentaires concernant :

10 L'importance économique de la maladie. Intrinsèquement elle ne paraît pas être très grande au Tchad ni dans le Nord-Cameroun sur le bétail zébu d'élevage transhumant. Le total des pertes est minime. Cette proposition ne paraît plus être exacte en République Centrafricaine où la maladie des muqueuses est apparue dans des troupeaux de bovins importés destinés soit au dressage soit à la reproduction; en ces circonstances les pertes économiques sont plus sévèrement ressenties.

Dans plusieurs foyers, il est apparu que les lésions cutanées de la maladie avait fait le lit de nombreux cas de streptothricose cutanée évoluant quelques semaines plus tard. On est donc en droit de se demander si cette virose, au même titre que tous les facteurs traumatisant la peau, n'est pas l'une des causes favorisantes de cette affection cutanée. Dans ces conditions, la maladie des muqueuses verrait son importance accrue indirectement. 
$2^{\circ}$ La symptomatologie de la maladie. Elle suit dans ses grandes lignes ce qui a été décrit ailleurs $(22,26)$. Seuls semblent devoir être notés la sévérité des symptômes cutanés de certains foyers, contrastant avec ceux qui ont été relevés en Amérique et en Europe $(8,22,28)$, et surtout l'existence de la diarrhée noire. C'est à dessein que nous insistons sur ce caractère, vraisemblablement corollaire de l'absence de rectite hémorragique. II est intéressant de noter au passage que MONTGOMERY en 1915 au Kenya avait lui aussi été frappé par la couleur noire de la diarrhée de la maladie qu'il étudiait (6).

30 Le diagnostıc différentiel. II ne semble pas nécessaire d'insister sur les difficultés qu'll présente sur le terrain. Point n'est donc besoin de recommander au clinicien de recourır au diagnostic expérimental mais Il paraît bon d'insister sur la simplicité des moyens à mettre en œuvre. Sur le terrain, ils peuvent se résumer en une précipitation en gélose conduite selon les normes habituellement admises pour la peste bovine avec les modifications que nous avons exposées au chapitre : matériel et méthodes et sur la figure 1. Cette réaction sera doublée d'un envoi de matériel suspect au laboratoire et éventuellement de 2 saignées espacées de 15 jours, destinées d̀ rechercher une montée d'anticorps.

40 Les mesures prophylactiques. Paradoxalement, elles concernent moins la maladie qui nous occupe que la peste bovine. En effet, il est bon de répéter avec SCÓTT (26), que «tout foyer suspect devra être traité comme s'il s'agissait de peste bovine jusqu'à ce qu'il soit prouvé qu'il ne s'agit pas de cette maladie ».

Valable pour les pays d'enzootie pestique, cette proposition l'est encore plus pour les territoires non infectés, si l'on se souvient que peste et maladie des muqueuses peuvent évoluer pour leur propre compte en certains foyers.

Dans les premiers territoires tels le Tchad et le Nord-Cameroun, I'application des mesures de prophylaxie sanitaire et médicale classiquement adoptées ne soulèvera pas de difficultés majeures.

Le problème peut être autre en R. C. A. et dans I'Adamaoua (Cameroun central), territoires où n'existe pas la peste bovine et où les vaccinations antipestiques ne sont pas pratiquées. La mise en place d'un dispositıf prophylactıque ne peut reposer que sur l'isolement du foyer ou sa destruction, toute introduction d'un virus-vaccin antipestique étant pour le moment écartée par les autorıtés sanitaires. C'est dire que les mesures mises en cuvre devront être imposées avec la plus grande vigueur et que devra être suivi comme une règle d'or le conseil donné plus haut par SCOTT.

Quant à la prophylaxie médicale spécifique de la maladie des muqueuses, elle ne paraît pas pour le moment être justiciable d'une action d'envergure. La raréfaction des foyers de peste bovine authentique en Afrique centrale mettra peut-être en évidence dans un proche avenir sa véritable importance.

Pour l'instant, tenant comple de ce qu'ont appris l'épizootıologie et les investigations sérologiques (75 p. 100 de bovins adultes avec des anticorps), tout programme de vaccination paraît être largement prématuré. S'ıl devait être étudié, il est vraisemblable qu'on l'orienteralt vers un virus-vaccin de culture cellulaire.

$\checkmark u$ sous les angles que nous venons d'évoquer, il ne paraît pas spécialement paradoxal d'affirmer que l'intérêt actuel que présente la maladie des muqueuses en Afrique centrale est dépendant de la peste bovine ; celle-ci disparue, l'autre ne présentera vraisemblablement que peu d'importance pour autant que ne se modifient pas les conditions socio-économiques des élevages tchadiens et nord-camerounais.

Institut d'Elevoge ef de Médecine Vétérnaire des Pays Tropicaux. Laboratoire de Recherches Vétérinaires de Farcha, Fort-Lamy, Tchad. 


\title{
SUMMARY
}

\author{
Mucosal Disease in central Africa. \\ Some clinical and epizootiological observations
}

\begin{abstract}
After having described the virological procedures carried out in order to identify the non-cytopathogenic strains of the virus of Mucosal Disease, the authors are reviewing the factors governing the epizootiology of the disease in central Africa; then the particularities of the disease observed in this region and the principles of the diagnosis are described. A serological survey showed that 75 p. 100 of the adult cattle have antibodies in their blood; these antibodies were found also in sheep, antelope and gazelle. The distribution of the antibodies by categories of age in cattle seems to indicate that in central Africa the disease occurs in epizootic outbreaks.
\end{abstract}

\section{RESUMEN}

La Enfermedad de las mucosas en Africa central. Observaciones clinicas y epizootiologicas

Los autores describen las técnicas virológicas utilizadas para identificar las cepas no citopatogenas del virus de la enfermedad de las mucosas.

Luego pasan en revista los factores determinando la epizootiologia de la enfermedad en Africa central; notan las particularidades de lo enfermedad encontrada en esta región asi como los elementos del diagnóstico. Una encuesta serológica indica que 75 p. 100 de los bovinos adultos tienen anticuerpos, tambien encontrados en las ovejas, los antilopes y 'as gacelas. La repartición de los anticuerpos por clases de edad en los bovinos parece demostrar que la enfermedad de las mucosas se desarolla por accesos epizooticos en Africa central.

\section{BIBLIOGRAPHIE}

1. Anonyme. - Deuxième caurs sur le diagnostic de la peste bovine. Rev. Elev. Med. Vet. Pays trop., 1963, $16: 443$.

2. BOGEL (K.). - Über die Verbreitung eines Virus der Mucosaldisease - Gruppe in Schafherden Süddentschlands Zbl. Vet, Med., 1964, 11 B : 687-692.

3. BÖGEL (K.), PROVOST (A.) et ENDERSRUCKLE (G.), - Hămmaglutinations-Hemmungsreaktion mit Masern Antigen bei Rinderpest. I. Anwendung in der Diagnostik. Zbl. Bakt. 1. (Org.), 1966, $199: 1-19$.

4. BOGEL (K.), PROVOST (A.) et ENDERSRUCKLE (G.). - Une réaction sérologique rapide de mesure des anticorps antibovipestiques. C. R. Ac. Sc., 1964, $259: 482-84$.

5. BÖGEL (K.) et VOSS (N. J.). - Serologische Untersuchungen über die Verbrei- tung des an der Mucosal Disease beteiligten Virus in Nord-Deutschland. Zbl. Vet. Med., 1964, 11 b : 11-19.

6. BROWN (R. D.) et SCOTT (G. R.). Mucosal disease complex. Vet. Rec., 1957, $69: 916$.

7. DARBYSHIRE (J.H.). - Agar gel diffusion studies with a mucosal disease of cattle. Il. A serological relationship beiween a mucosal disease and swine fever. Res. Vet. Sc., 1962, $3: 125-128$.

8. DOW (C.), JARRETT (W. F. H.) et MCINTYRE (W. I. M.). - A disease of cattle in Britain resembling the virus diarrhoea-Mucosal disease complex Vet. Rec., $1956,68: 620-623$.

9. GILLESPIE (J. H.), MADIN (S. H.) et DARBY (N.B.). - Cellular resistance in 
tissue culture, induced by noncytopathogenic strains, to a cytopathogenic strain of virus diarrhea virus of cattle. Proc. Soc. exp. Biol. Med., 1962, 110 : 248-250.

10. KAHRS (R.), ATKINSON (G.), BAKER (J. A.), CARMICHAEL (L.), COGGINS (L.), GILLESPIE (J.), LANGER (P.), MARSHALL (V.), ROBSON (D.) et SHEFFY (B.). Serological studies on the incidence of bovine virus diarrhea, infectious bovine rhinotracheitis, bovine myxovirus parainfluenza-3 and Leptospira pomona in New-York state. Cornell Vet., 1964, 54 : 360-369.

11. KASSEM (H.). - A report on semi-mucosal disease in the egyptian region (U.A.R.). Bull. O. I. E., 1961, $56: 41-46$.

12. LAMBELIN (G.) et ECTORS (F.). - Noie préliminaire sur une maladie des bovidés ayant fait son apparition en Ituri en 1958. Ann. Soc. belge Med. trop., 1960, 40 : 183187.

13. LEPISSIER (H. E.). - Campagne conjointe contre la peste bovine. CCTA-P. C. no 15. Bull. epiz. Dis. Afr., 1963, 11 : 259-264.

14. MASON (J.H.) ef NEITZ (W.O.). - Erosive stomatitis of cattle. Ond. J. Vet. Sc., 1940, $15: 159-173$.

15. MAURER (F. D.), JONES (T. C.), EASTERDAY (B.) et DeTRAY (D.). - Pathology of rinderpest. Proceed. $92^{\text {nd }}$ Ann. meet. Am. Vet. Med. Asso., 1955, 201-211.

16. MILLS (J. H. L.), NIELSEN (S. W.) et LUGIN-BUHL (R. E.). - Current status of bovine mucosal disease. J. A. V. M. A., 1965, $146: 691-696$.

17. MORNET (P.) et GUERRET (M.). - Les lésions cutanées de la peste bovine. Bull. Acod. Vet., 1950, 23 : 283-285.

18. NEWBERNE (J.W.), ROBINSON (V.B.) et ALTER (M. L.). - Incidence of infectious bovine rhinotracheitis and bovine virus diarrhea. Vet. Med. (U. S. A.), 1961, 56 : 395398.
19. OTTE (E.). - A note on a « rinderpest-like disease » in the Sudan and in Ethiopia. Bull. epiz. Dis. Afr., 1961, $9: 215-226$.

20. OTTE (E.) et PECK (E. F.). - A note on a rinderpest-like disease of cattle in Ethiopia. Bull. epiz. Dis. Afr., 1960, 8 : 203-216.

21. PLOWRIGHT (W.). - Rinderpest. Vet. Rec., 1965, $77: 1431-1438$.

22. PRITCHARD (W.R.). - The bovine viral diarrhea. - Mucosal disease complex. Adv. Vet. Sc., 1963, $8: 1-47$.

23. PROVOST (A.) et BORREDON (C.). - Les différents aspects du diagnostic clinique et expérimental de la peste bovine. Rev. Elev. Med. Vet. Poys trop., 1963, 16 : 445-526.

24. PROVOST (A.), BORREDON (C.) et FEREOL (C.). - Note sur la rhinotrachéite infectieuse bovine en Afrique. Isolement du virus ; enquête sérologique. Rev. Elev. Med. Vet. Poys trop., 1964, 17 : 187-196.

25. PROVOST (A.), BORREDON (C.) et QUEVAL (R.). - Une hypogammaglobulinémie essentielle des bovins d'Afrique Centrale, cause d'erreur dans les enquêtes sérologiques. Rev. Elev. Med. Vet. Pays trop., $1965,18: 385-393$.

26. SCOTT (G. R.). - The new pseudorinderpests. Bull. epiz. Dis. Afr., 1964, 12 : 287298.

27. SMITH (R. E.), CLARK (G. W.), REYNOLDS (I. M.) et DAMON (R. A.). Serologic survey for infectious bovine rhinotracheitis and bovine viral diarrhea antibodies. J. Am. Vef. Med. Ass., 1964, 145 : 40-42.

28. TOURNUT (J.), LACAZE (B.), REDON (P.) et LAPORTE (J.). - Identification de la maladie muqueuse dans le Sud-Ouest de la France. Rev. Med. Vet., 1961, 112 : 81-90.

29. WACHENDÖRFER (G.). - Zur Diagnose der Mucosal Disease des Rindes mit Hilfe des Agargel-Testes. Deut. Tierär. Woch., 1965. 72 : 413-417. 